\section{Check for updates}

Cite this: Med. Chem. Commun. 2018, 9, 1249

Received 30th May 2018,

Accepted 10th July 2018

DOI: $10.1039 / \mathrm{c} 8 \mathrm{md} 00273 \mathrm{~h}$

rsc.li/medchemcomm

\title{
Chemical modulation of transcription factors
}

\author{
Bianca Wiedemann,† Jörn Weisner† and Daniel Rauh (D)*
}

\begin{abstract}
Transcription factors (TFs) constitute a diverse class of sequence-specific DNA-binding proteins, which are key to the modulation of gene expression. TFs have been associated with human diseases, including cancer, Alzheimer's and other neurodegenerative diseases, which makes this class of proteins attractive targets for chemical biology and medicinal chemistry research. Since TFs lack a common binding site or structural similarity, the development of small molecules to efficiently modulate TF biology in cells and in vivo is a challenging task. This review highlights various strategies that are currently being explored for the identification and development of modulators of Myc, p53, Stat, Nrf2, CREB, ER, AR, HIF, NF-kB, and BET proteins.
\end{abstract}

\section{Introduction}

Transcription factors (TF) are the final players of signal transduction cascades that often begin with extracellular ligand binding events, followed by signal integration and processing and ultimately result in initiation or repression of target gene transcription.

Ever since the first discovery of the crucial roles TFs play in nearly every fundamental physiological and pathophysiological process, enormous efforts have been undertaken to identify pharmacologic and therapeutic modulators of these transcriptional regulators. ${ }^{1}$

Technische Universität Dortmund, Fakultät für Chemie und Chemische Biologie, Otto-Hahn-Strasse 4a, D-44227 Dortmund, Germany.

E-mail: daniel.rauh@tu-dortmund.de; Fax: +49 (0)231 755 7082;

Tel: +49 (0)231 7557080

$\dagger$ These authors contributed equally to this work.

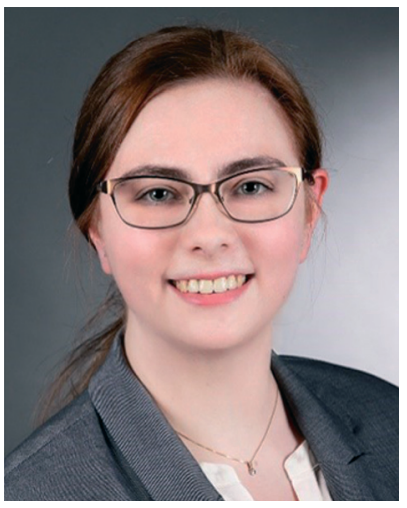

Bianca Wiedemann
Bianca Wiedemann studied Chemical Biology at TU Dortmund University (Germany). Throughout the Bachelor program, she deepened her knowledge in the preparation of organometallic molecules of main group elements in the group of Klaus Jurkschat. She joined the group of Daniel Rauh for her Master thesis, followed by $P h D$ studies in the field of Medicinal Chemistry. Her focus is on the development and structural characterization of small molecules and stapled peptides as modulators for misregulated transcription factor activity.
However, due to insufficient knowledge of overall structural features, appropriate small molecule binding sites, regulatory mechanisms, and interaction partners as well as signaling pathway crosstalk, only a limited number of pathway-, target-, and/or disease-specific TF modulators has been identified and characterized to date. On this basis, TFs have traditionally been referred to as "undruggable". 2 Nevertheless, a few substances have entered pre-clinical or even clinical development. For only a small subset of TFs, namely ligandactivated nuclear receptors, targeted approaches have led to the development of impactful, highly selective, and potent small molecule modulators for use in the clinic for the treatment of diverse forms of cancer. ${ }^{3}$ In contrast, for traditional targets such as protein kinases, numerous selective small molecule inhibitors have been developed and characterized. Conversely, the arrangement of signaling pathways enables the emergence of mechanisms that can render targeted

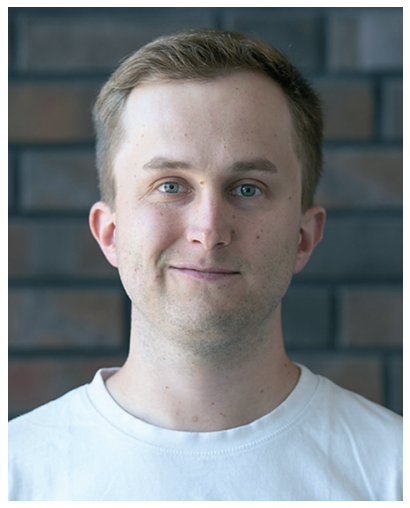

Jörn Weisner
Jörn Weisner studied Chemical Biology at TU Dortmund University (Germany). For his Bachelor studies, he joined the group of Prof. Philippe Bastiaens at the Max Planck Institute of Molecular Physiology. He obtained his MSc on covalent-allosteric protein kinase inhibitors under the supervision of Prof. Daniel Rauh. In his PhD he facilitates biochemical and cellular assay platforms for the identification and characterization of small molecule modulators of protein kinases and transcription factors. 
approaches with kinase inhibitors ineffective. Only a small number of kinase inhibitors are available that selectively modify the activity of a single downstream TF. Among these, FDA-approved Janus kinase (JAK) inhibitors ruxolitinib and tofacitinib downregulate Stat phosphorylation and subsequent Stat-driven gene transcription. ${ }^{4,5}$ Moreover, experimental inhibitors have been characterized for NF- $\kappa \mathrm{B}$-inducing kinase (NIK) to prevent non-canonical NF- $\kappa \mathrm{B}$ signaling. ${ }^{6}$ Therefore, a focus on compounds that act immediately on the transcriptional level can help with the development of novel therapeutic strategies.

Generally, TFs share a modular structure comprising common elements such as DNA-binding domains (e.g., zinc finger, basic helix-loop-helix, basic leucine zipper, Fig. 1) and trans-activating domains that point towards broadly applicable approaches for molecular modulation. ${ }^{7}$ Reported strategies include intervention at the level of DNA binding, chromatin remodeling, TF dimerization, cofactor interaction, and upstream regulation. ${ }^{2}$ Furthermore, TFs represent promising molecular targets with respect to avoidance and/or overcoming of the emergence of resistances or bypass mechanisms caused by therapeutic intervention of dysregulated upstream proteins. ${ }^{8}$ This central and ultimate role in signal transduction implicates the significant potential to efficiently target a broad diversity of cancers, to overcome acquired resistances, and to avoid bypass signaling by addressing key transcriptional regulators.

In this review, we will emphasize recent strategies towards targeted, pharmacologic modulation of TFs as targets in relevant disease states and highlight advantages, limitations and drawbacks of published approaches. Of note, Table 1 presents

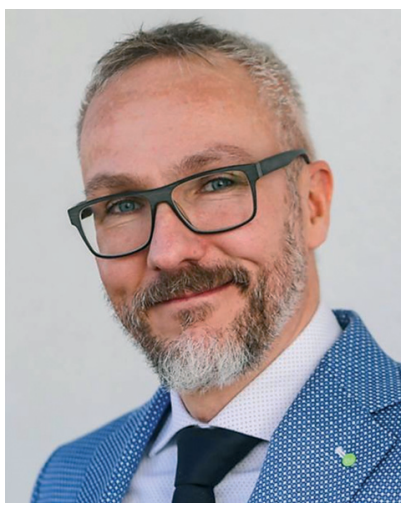

Daniel Rauh
Daniel Rauh studied pharmacy at the University of Greifswald. After completing his Diploma with Gregor Radau and HansHartwig Otto in 1999, he completed his PhD with Gerhard Klebe at the Philips-Universität Marburg in 2003. After postdoctoral research with Milton Stubbs in Halle and Kevan Shokat in San Francisco, he became a junior group leader at the Chemical Genomics Centre of the MPI Dortmund. In 2010 he became Professor of Chemical Biology at TU Dortmund University. Since 2013 he has been Professor and Chair of Chemical Biology and Medicinal Chemistry. His research focuses on the structure-based design and synthesis of small molecules for modulating biological systems. He is a co-founder of the Zentrum für Integrierte Wirkstoffforschung (ZIW) at TU Dortmund University and coordinates the Drug Discovery Hub Dortmund (DDHD), which aim at translating basic academic research into pharmaceutical application. a summarized overview of a selection of target TF-relevant crystal structures with their respective modes of action, binding sites, and protein data bank identifiers. A selection of approved drugs targeting TFs and their therapeutic use is summarized in Table 2. Moreover, pathway schemes for selected TFs are shown in Fig. 2. To fuel the understanding of the binding mode of the discussed modulators, we generated augmented reality structures, which can be assessed by the respective QR codes using the app Augment (AUGMENT, Augment USA, Inc.) which is readily available for android and iOS (http://www. augment.com/augmented-reality-apps/). ${ }^{9}$

\section{Myc}

Myc is a well-studied TF which regulates several biological functions such as cell growth, apoptosis, differentiation, and oncogenic transformation. ${ }^{10}$ Family members include MycN which was found to be activated in neuroblastoma and MycL1 which was identified in small-cell lung cancer. ${ }^{11}$ Several posttranslational modifications of Myc have been identified in the past. However, the biological role of $O$-glycosylation and acetylation remains to be fully understood und will provide new insight in the regulation of Myc valuable for the design of modulators in the future. ${ }^{12}$ Other modifications like the phosphorylation of Thr58 through GSK3 are better understood. This promotes the binding of FBXW7 which recruits SCF and leads to the ubiquitinylation and subsequent proteasomal degradation of Myc. ${ }^{10}$ The transcriptional activity of Myc is regulated through its primary interaction partner Max (Myc-associated factor X). ${ }^{13}$ Formation of the heterodimer is mediated by a basic helix-loop-helix leucine zipper. As a dimer, Myc:Max binds to enhancer E-boxes with a canonical sequence (CACGTG) and enhances transcriptional activity in the respective areas. ${ }^{14,15}$ Designing small molecule inhibitors of this PPI interface is one of the promising strategies applied in Myc inhibition. Besides this function, Myc is able to interact with several other proteins like TRRAP (transformation-transactivation domain associated protein), ${ }^{16} \mathrm{p}$-TEFb (positive transcription elongation factor), ${ }^{17}$ other transcription factors like Miz-1 responsible for cell cycle progression ${ }^{18}$ and SP1 responsible for transcriptional repression. ${ }^{19}$ A promising strategy to prevent Myc transcription is the induction of quadruplexes of the nuclease hypersensitive element (NHE) III1 in the promotor region of Myc. ${ }^{20}$ Since under physiological conditions this promotor region is ordered preferred in Watson-Crick base pairs, ${ }^{21}$ this strategy might prove more successful than simple quadruplex binders. A state of the art overview about these strategies involving the Myc promotor quadruplexes is given in the review by Chen and coworkers. ${ }^{22}$ Hence, this topic will not be further discussed in our review. Small molecules targeting the Myc:Max interaction starting from peptidomimetics and leading up to molecules found through screening experiments are also covered in the above mentioned review.

Recently Chauhan and coworkers published an oxadiazole-based small molecule (1, Fig. 3) which is able to 

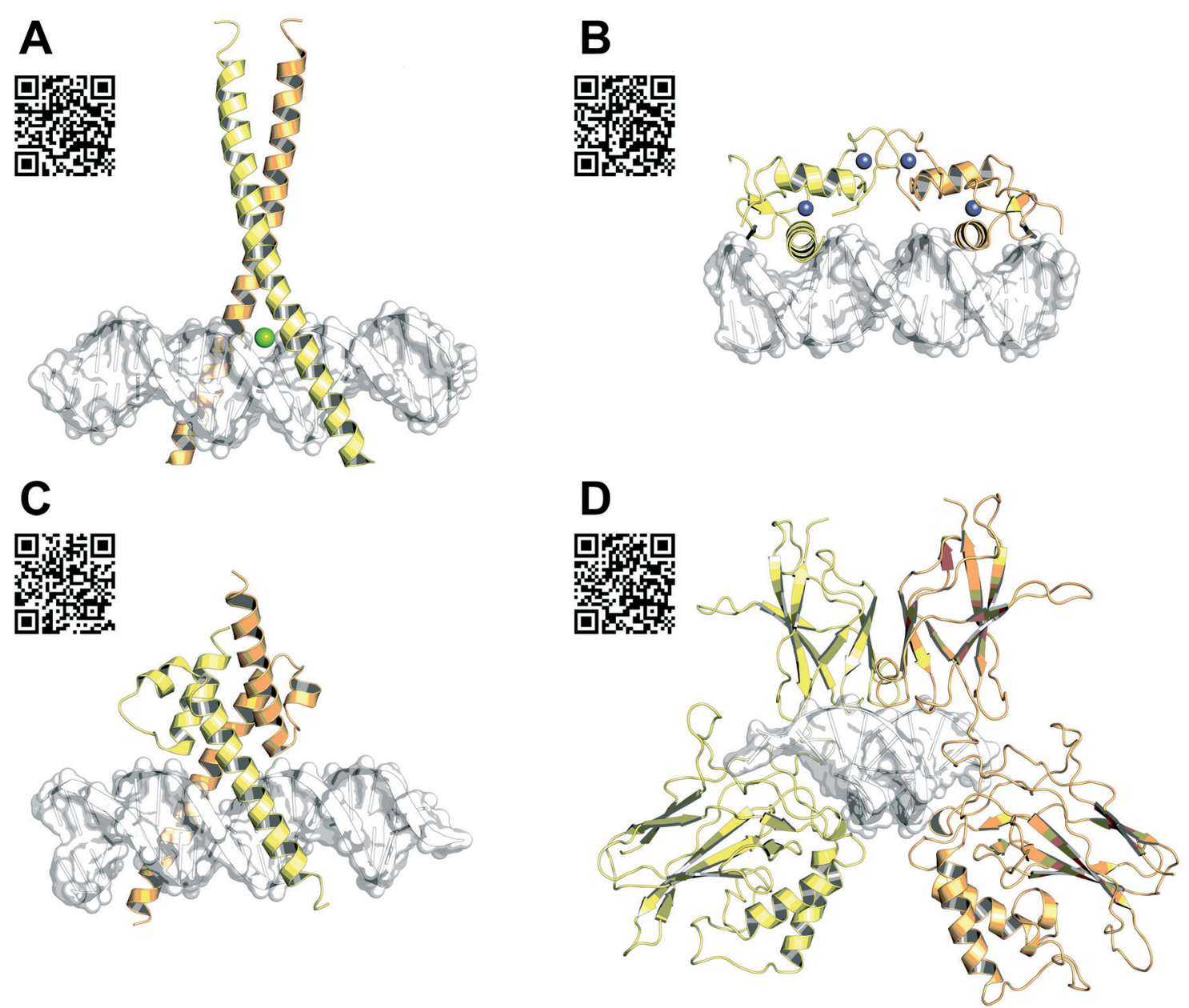

Fig. 1 Crystal structures of TF DNA-binding domains. A) CREB basic leucine zipper (bZIP) homodimer bound to somatostatin cAMP response element (SSCRE) of sequence CCTTGGCTGACGTCAGCCAAG (PDB 1dh3); B) homodimer of the estrogen receptor DNA-binding domain (zinc finger motif) in complex with ER response element of sequence CCAGGTCACAGTGACCTG (PDB 1hcq); C) heterodimeric complex of HIF-2 $\alpha$ :ARNT(HIF$1 \beta$ ) bHLH motifs bound to hypoxia-response element (HRE) of sequence CACGACCCGCACGTACGCAGC (PDB: 4zpk); D) immunoglobulin-like Rel homology domain homodimer of p50 bound to kappaB motif of sequence TGGGAATTCCC (PDB 1nfk). The QR codes can be visualized by the app Augment.

inhibit the formation of the trimeric complex of Myc:Max: DNA. EMSA revealed an $\mathrm{IC}_{50}$ of $34.8 \mu \mathrm{M}$ which shows a two-fold selectivity over the Max homodimer. A coimmunoprecipitation assay underlined the hypothesis that the oxazole can prevent the Myc:Max dimer formation in a concentration dependent manner. Further studies revealed its ability to inhibit the expression of a Myc-dependent luciferase reporter and lock cells in the $G_{0} / G_{1}$ phase of the cell cycle. ${ }^{23}$ Special care has to be taken for molecules like this to ensure a high level of selectivity for the protein-DNA-complex. Off-target effects on other proteins which interact with Myc have to be excluded and the binding mode clarified before such molecules can serve as a promising tool compound for the further understanding of the Myc-Max interplay and drive the structure-based development of potent small molecules.

Two previously reported small molecules $(2 \mathbf{a} / \mathbf{b})$, which were able to inhibit the Myc:Max dimer formation, were reversibly linked via different connectors. This linkage occurred in situ thus proving the synergistic effect. This event was evaluated in proliferation assay $(10 \mu \mathrm{M})$, SPR $\left(K_{\mathrm{d}}=8.6 \mu \mathrm{M}\right)$, ELISA $\left(\mathrm{IC}_{50}=3.3 \mu \mathrm{M}\right)$ and EMSA which revealed a dose dependent behavior of the molecules. ${ }^{24}$ However, the small molecule 2a, which was originally identified from a yeast twohybrid screening, comprises different motifs commonly associated with pan assay interference compounds (PAINS). ${ }^{25,26}$ The core element of 2 a consists of an ene-rhodanine, which can complex metal ions and covalently modify proteins. ${ }^{26}$ Moreover, the diol structure on the eastern part might be prone to unspecific binding. Since PAINS often lead to falsepositive screening results and subsequent futile efforts when it comes to chemical optimization, these compounds need to undergo very critical evaluation of their on-target effects. Evaluation of the binding mode is the key for the start of a structure guided optimization of these molecules. Following this path will lead to the generation of molecules suitable for cellular studies and enhance the understanding of the biological role of Myc and its interaction partners. 
Table 1 Selected overview of small molecule transcription factor modulators, their modes and sites of action, and the PDB entry codes of the respective $\mathrm{X}$-ray structures of the target TFs

\begin{tabular}{|c|c|c|c|c|c|}
\hline Strategy & $\mathrm{TF}$ & Compound & Mode of action & Binding site & PDB \\
\hline $\begin{array}{l}\text { Covalent stabilization of Y220C } \\
\text { mutant }\end{array}$ & p53 & $6 \mathrm{SM}$ & $\begin{array}{l}\text { Alkylation of Cys182 and subsequent } \\
\text { stabilization }\end{array}$ & Side chain of Cys182 & 5LAP \\
\hline Inhibitor of p53:MDM2 interactions & MDM2 & p53 peptide & Protein-protein interaction disruptor & p53 binding site & 4HFZ \\
\hline Inhibitor of $\mathrm{p} 53: \mathrm{MDM} 2$ interactions & MDM2 & I09/RG7388 (6) & Protein-protein interaction disruptor & p53 binding site & $4 \mathrm{JRG}$ \\
\hline Inhibitor of p53:MDM2 interactions & p53 & NUT/nutlin-3a & Antagonist of MDM2 & p53 binding site & 4HG7 \\
\hline Inhibitor of Keap1:Nrf2 interactions & Keap1 & IQK & Protein-protein interaction disruptor & Nrf2 binding site & $4 \mathrm{IQK}$ \\
\hline Inhibitor of Keap1:Nrf2 interactions & Keap1 & $41 \mathrm{P}(12)$ & Protein-protein interaction disruptor & Nrf2 binding site & $4 \mathrm{XMB}$ \\
\hline Inhibitor of Keap1:Nrf2 interactions & Keap1 & $2 \mathrm{FS}$ & Protein-protein interaction disruptor & Nrf2 binding site & 4N1B \\
\hline Inhibitor of Keap1:Nrf2 interactions & Keap1 & TX6/TX64014 & Protein-protein interaction disruptor & Nrf2 binding site & 5DAD \\
\hline Positive stimulation of ER signaling & ER & Estradiol & Stabilizing active conformation, agonist & $\begin{array}{l}\text { Ligand binding } \\
\text { domain }\end{array}$ & 1ERE \\
\hline Selective modulation of ER signaling & ER & 4-Hydroxytamoxifen & Stabilizing inactive conformation, SERM & $\begin{array}{l}\text { Ligand binding } \\
\text { domain }\end{array}$ & 3ERT \\
\hline Selective modulation of ER signaling & ER & Bazedoxifene & Stabilizing inactive conformation, SERM & $\begin{array}{l}\text { Ligand binding } \\
\text { domain }\end{array}$ & $4 \mathrm{XI} 3$ \\
\hline Induction of ER degradation & ER & AZD9496 (22) & Selective estrogen receptor downregulator & $\begin{array}{l}\text { Ligand binding } \\
\text { domain }\end{array}$ & $5 \mathrm{ACC}$ \\
\hline Positive stimulation of AR signaling & $\mathrm{AR}$ & Testosterone & Stabilizing active conformation, agonist & $\begin{array}{l}\text { Ligand binding } \\
\text { domain }\end{array}$ & 2AM9 \\
\hline Inhibition of AR signaling & AR & Bicalutamide (23) & Stabilizing inactive conformation, NSAA & $\begin{array}{l}\text { Ligand binding } \\
\text { domain }\end{array}$ & $1 \mathrm{Z95}$ \\
\hline Destabilizing HIF-2 $\alpha$ :ARNT complex & HIF & 28 & $\begin{array}{l}\text { Allosteric protein-protein interaction } \\
\text { disruptor }\end{array}$ & $\begin{array}{l}\text { HIF- } 2 \alpha \text { PAS B } \\
\text { domain }\end{array}$ & $4 \mathrm{XT} 2$ \\
\hline Destabilizing HIF-2 $\alpha$ :ARNT complex & HIF & РT2399 (29) & $\begin{array}{l}\text { Allosteric protein-protein interaction } \\
\text { disruptor }\end{array}$ & $\begin{array}{l}\text { HIF- } 2 \alpha \text { PAS B } \\
\text { domain }\end{array}$ & 5UFP \\
\hline Disrupting HIF:pVHL complex & HIF & ZTD & Protein-protein interaction inhibitor & $\begin{array}{l}\text { OH-Pro564 binding } \\
\text { site }\end{array}$ & 3ZTD \\
\hline Disrupting HIF:pVHL complex & HIF & VH298 (34) & Protein-protein interaction inhibitor & $\begin{array}{l}\text { OH-Pro564 binding } \\
\text { site }\end{array}$ & 5LLI \\
\hline $\begin{array}{l}\text { Inhibition of non-canonical NF- } \kappa \mathrm{B} \\
\text { pathway }\end{array}$ & $\mathrm{NF}-\kappa \mathrm{B}$ & $\mathrm{T} 28$ & ATP-competitive inhibition of NIK & $\begin{array}{l}\text { NIK ATP binding } \\
\text { site }\end{array}$ & $4 \mathrm{IDT}$ \\
\hline $\begin{array}{l}\text { Inhibition of non-canonical NF- } \kappa \mathrm{B} \\
\text { pathway }\end{array}$ & $\mathrm{NF}-\kappa \mathrm{B}$ & oWC & ATP-competitive inhibition of NIK & $\begin{array}{l}\text { NIK ATP binding } \\
\text { site }\end{array}$ & $4 \mathrm{G} 3 \mathrm{E}$ \\
\hline $\begin{array}{l}\text { Inhibition of non-canonical NF- } \mathrm{KB} \\
\text { pathway }\end{array}$ & $\mathrm{NF}-\kappa \mathrm{B}$ & $76 Z$ & ATP-competitive inhibition of NIK & $\begin{array}{l}\text { NIK ATP binding } \\
\text { site }\end{array}$ & $5 \mathrm{~T} 8 \mathrm{O}$ \\
\hline Inhibition of acetyl lysine binding & Brd4 & JQ1 (43) & Protein-protein interaction disruptor & Ac-Lys binding site & $3 \mathrm{ONI}$ \\
\hline Inhibition of acetyl lysine binding & Brd4 & 47 & Protein-protein interaction disruptor & Ac-Lys binding site & $5 \mathrm{~J} 0 \mathrm{D}$ \\
\hline
\end{tabular}

Table 2 Overview of examples of approved drugs of transcription factors, their commercial name, active ingredient, mode of action, therapeutic use and date of first approval (FDA)

\begin{tabular}{|c|c|c|c|c|c|}
\hline Commercial name & $\mathrm{TF}$ & Active ingredient & Mode of action & Therapeutic use & $\begin{array}{l}\text { First } \\
\text { approval }\end{array}$ \\
\hline Tecfidera, Fumaderm & Nrf2 & Dimethyl fumarate & Alkylation of Keap1 & Multiple sclerosis, psoriasis & 2013 \\
\hline Feminone, Lynoral and others & ER & Ethinyl estradiol & ER agonist & Contraceptive & 2001 \\
\hline Faslodex & ER & Fulvestrant & ER antagonist & $\begin{array}{l}\text { Treatment of HR-positive metastatic breast } \\
\text { cancer in postmenopausal women }\end{array}$ & 2002 \\
\hline Femtrace, Femring & ER & Estradiol acetate & ER agonist & Contraceptive & 2003 \\
\hline Femtab, Progynova and others & ER & Estradiol valerate & ER agonist & Contraceptive & 2010 \\
\hline Osphena & ER & Ospemifene & ER modulator & Dyspareunia & 2013 \\
\hline Cosudex, Kalumid and others & AR & Bicalutamide (23) & AR antagonist & Treatment of prostate cancer & 1995 \\
\hline Nilandron, Anadron and others & AR & Nilutamide & AR antagonist & Treatment of prostate cancer & 1996 \\
\hline Xtandi & AR & Enzalutamide (24) & AR antagonist & Treatment of prostate cancer & 2012 \\
\hline Andriol, Nebido and others & AR & Testosterone undecanoate & AR agonist & Treatment of low testosterone levels in men & 2014 \\
\hline Erleada & AR & Apalutamide (25) & AR antagonist & Treatment of prostate cancer & 2018 \\
\hline
\end{tabular}




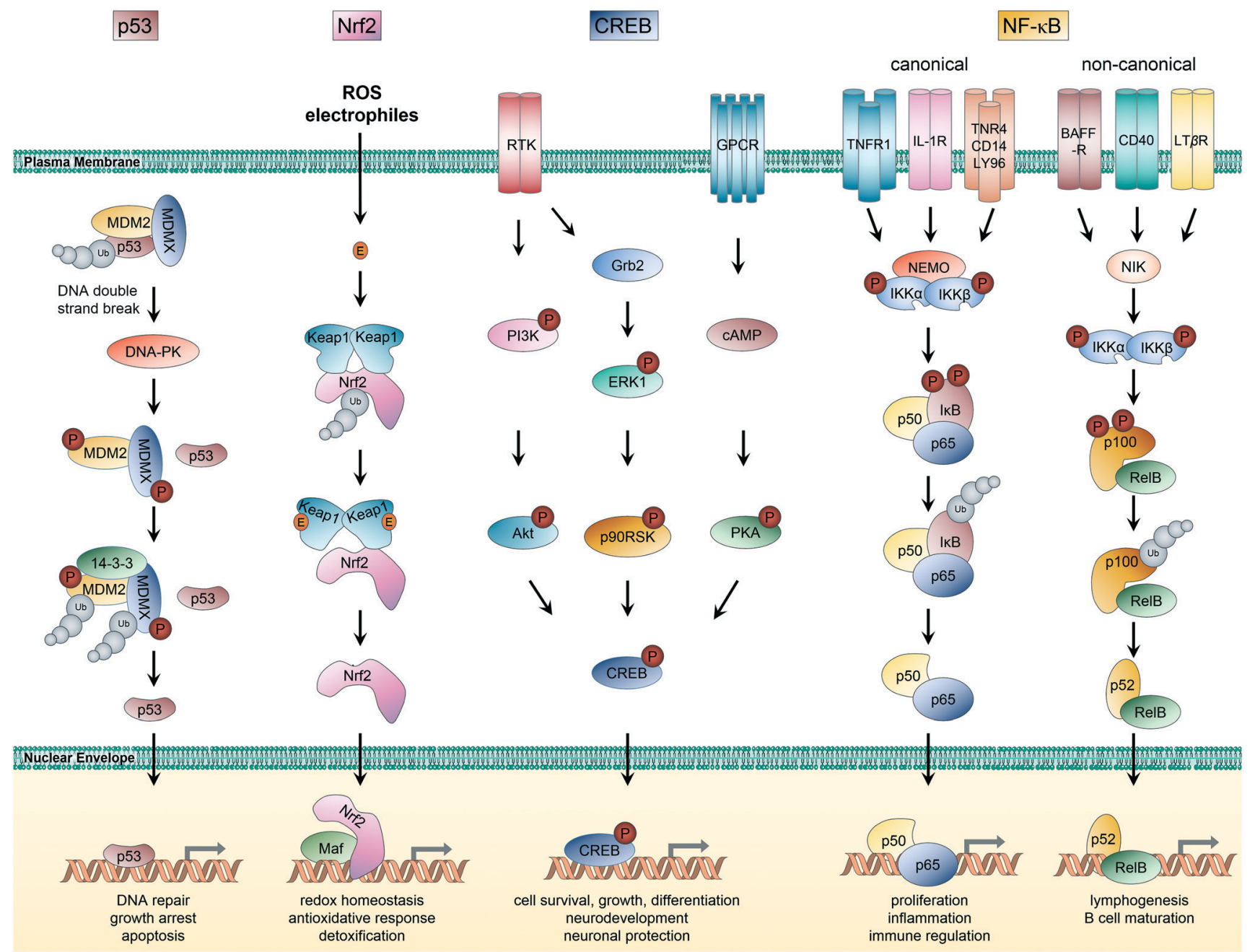

Fig. 2 Selected excerpts of TF pathways highlighted within this review, i.e. p53, Nrf2, CREB, and NF- $\mathrm{B}$.<smiles>COC(=O)c1ccc(Nc2ccc([N+](=O)[O-])c3nonc23)c(-c2ccc([N+](=O)[O-])cc2)c1</smiles>

1<smiles>CCc1ccc(/C=C2\SC(=O)N(CCC3C4CCC3C(O)C4O)C2=O)cc1</smiles>

2a<smiles>O=C(NCc1ccccc1[Se]O)c1ccccc1Nc1ccc([N+](=O)[O-])c2nonc12</smiles>

2b

Fig. 3 Chemical structures of modulators of Myc activity (1-2a/b).

\section{p53}

The interplay between p53 and MDM2 is a critical network node in the regulation of tumor suppression. MDM2 as well as MDMX are tight regulators of p53 activity. Binding to p53 results in ubiquitinylation, thus marking the protein for proteasomal degradation. Although MDMX is reported to have less impact on the p53 pathway, MDMX null mice die during embryogenesis. This phenotype can be rescued in a p53-null background. ${ }^{27}$ MDM2 and MDMX are sensitive to the deubiquitinase USP2a leading to accumulation of both proteins and abrogation of p53 activity. This leads to a negative feedback loop between p53 and MDM2. Various p53 independent functions of MDM2 and MDMX have been reported which include: association with the Mre:Rad50:Nbs1 DNA repair complex to inhibit DNA break repair, ${ }^{28}$ inhibition of TGF $\beta$ and subsequent downregulation of SMAD proteins responsible for tumor suppression and promotion; ${ }^{29}$ regulation of E2F1, a TF regulating cell cycle genes, ${ }^{30}$ and growth promotion in cells with activated K-Ras through CDK1, c-Jun 
and c-Myc. ${ }^{31}$ Under stressed conditions MDM2 undergoes phosphorylation which abrogates p53 binding. ${ }^{32}$ Activation of p53 renders tumor cells unable to incorporate thymidine in the DNA, thus progression through the cell cycle is suspended. ${ }^{33}$ Because of this p53 is often termed "guardian of the genome". Other regulatory mechanisms of p53 include posttranslational modification through various kinases which is often related to elongated lifetime of the protein due to inhibition of MDM2 binding. ${ }^{34}$ Guided by the crystal structure of a p53 peptide bound to MDM2 (PDB: 4hfz; Fig. 4) numerous molecules inhibiting this PPI have been described. Their potential and applications with regard to (pre)clinical development are discussed in a different review. ${ }^{35}$

Based on the research of nutlin derivatives and the clinical development of RG7112 (3), Ding and coworkers designed and synthesized new molecules with an altered core scaffold.

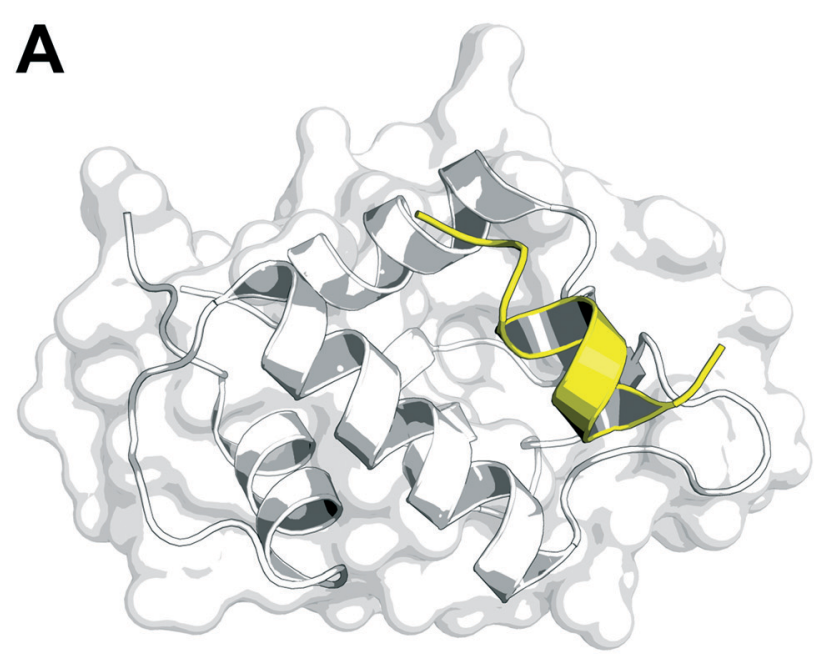

B
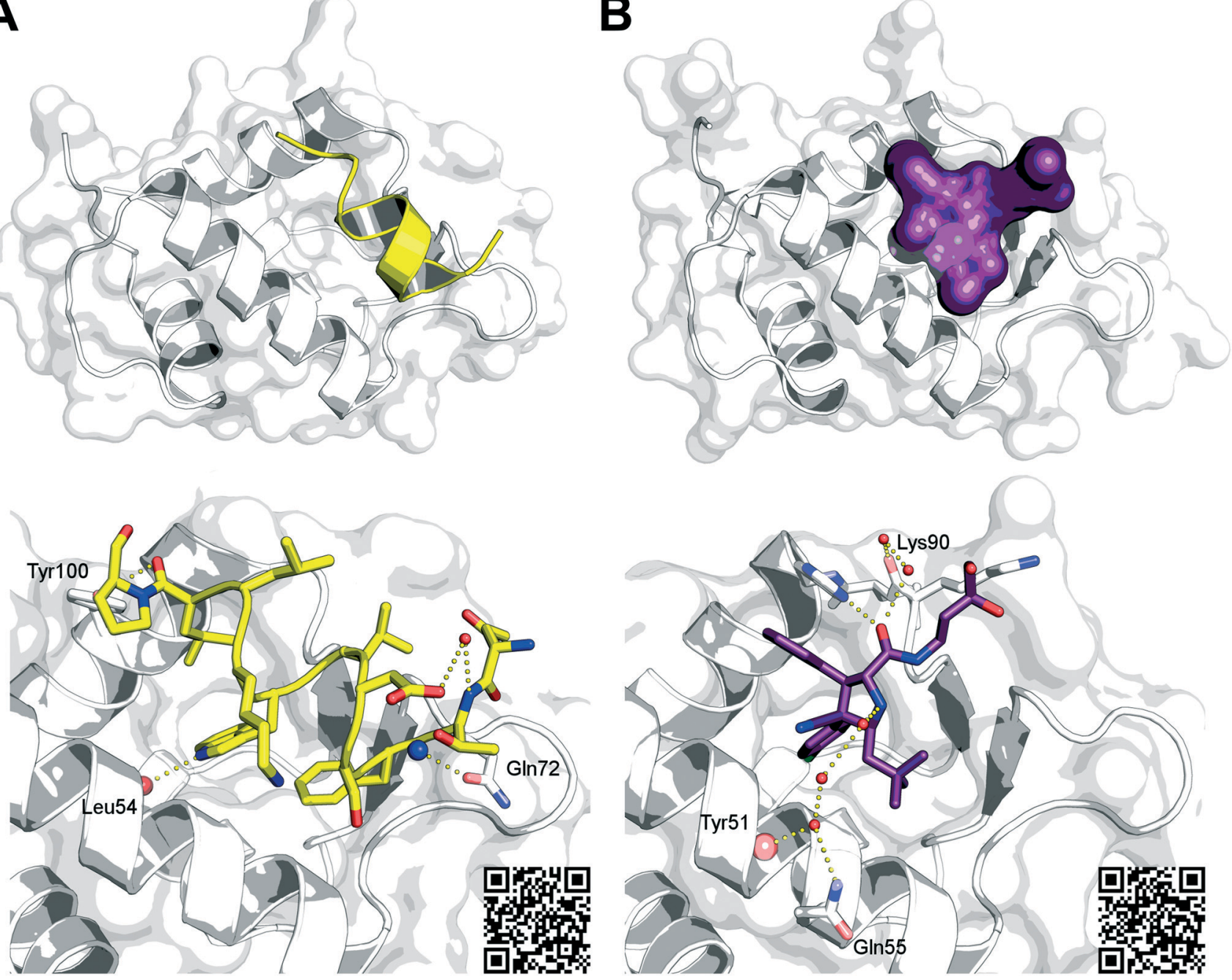

C
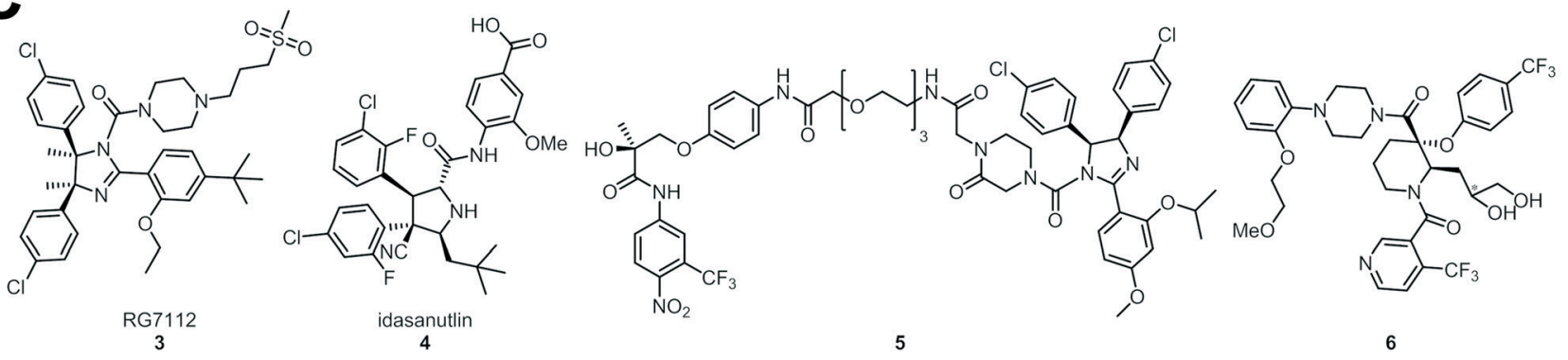

Fig. 4 Crystal structure of MDM2 in complex with a p53-derived peptide (A, yellow, PDB 4hfz) and in complex with small molecule inhibitor 4 (B, purple, PDB 4jrg). Both molecules occupy the dimerization site of MDM2:p53 thereby disrupting this interaction (non-interacting side chains are not shown for clarity purposes). C) Chemical structures of modulators of p53 (3-6). The QR codes can be visualized by the app Augment. 
One of these was crystallized in complex with MDM2 (PDB: 4jrg; Fig. 4), which served as a starting point for new derivatives. One of these molecules, which was later termed idasanutlin (4), exhibited good activity in an HTRF assay (6 $\mathrm{nM})$ and the MTT assay $(0.03 \mu \mathrm{M}$; average of SJSA1, RKO and HCT116 cells). This molecule was able to induce dosedependent p53 stabilization, cell cycle arrest, and apoptosis in cancer cells expressing wild-type p53. Additionally, the compound could achieve in vivo efficacy against SJSA1 osteosarcoma xenografts in nude mice. ${ }^{36}$ This potent MDM2:p53 inhibitor entered clinical trials for various applications. These include phase 1 to phase 3 trials for leukemia, plasma cell myeloma, and solid tumors. Within the next years the studies will show if this nutlin derivative can retain its excellent activity in clinical applications. Moreover, nutlin has gained attention as use for proteolysis-targeting chimeras (PROTACs). ${ }^{37}$ Schneekloth and coworkers combined nutlin with a SARM (5) and could prove the proteasomal degradation of the androgen receptor (AR) through addition of this complex. Next to other molecules like VHL and CRBN-based molecules this compound class has the potential for therapeutic means beside the activation of $\mathrm{p} 53$.

Another series of potent MDM2:p53 inhibitors composed of a central substituted piperidine moiety (6) was described by $\mathrm{Ma}$ and coworkers. Both diastereomers exhibited low nanomolar potency with an $\mathrm{IC}_{50}$ of $20 \mathrm{nM}$, as determined by fluorescence polarization assay. Evaluation of their activity in SJSA-1 cells indicated low micromolar activity in the range of $0.5 \mu \mathrm{M} .{ }^{38}$ Despite their potency, neither a binding mode nor a binding site was specified, increasing the difficulty for compound optimization.

As an alternative to traditional small molecules, stapled peptides have caught the attention of many scientists leading to an impressive increase of publications in this field, highlighting the potential importance of such molecules for future probe and drug development. These stapled peptides can overcome some of the limitations that classical small molecules tend to suffer from, such as limited binding affinities to shallow surfaces and toxic metabolites. Nevertheless, several disadvantages of peptide therapeutics have to be addressed, such as poor or no oral availability, acidic and enzymatic degradation in the gastrointestinal tract and poor cell permeability. Strategies to overcome these limitations include the above mentioned cyclization, $N$-methylation and addition of cell penetrating small peptides to the sequence.

Being developed by Aileron technologies, the stapled peptide ALRN-6924 is successfully passing phase 1 clinical trials for solid tumors and lymphomas (NCT02909972). ${ }^{39}$ This stapled peptide can inhibit the interactions between p53 and MDM2 as well as those between MDMX and p53. Currently, a phase $2 \mathrm{a}$ trial to determine the safety and tolerability of ALRN-6924 in patients with advanced solid tumors or lymphomas expressing wild-type p53 is on its way (NCT02264613). ${ }^{40}$ The results from this study will prove if ALRN-6924 has the potential to become the first stapled peptide therapeutic on the market.

\section{Stat}

The TF Stat (signal transducers and activators of transcription) and its activating JAK kinases were first identified as building a pathway that mediates interferon signaling. ${ }^{41}$ Stat proteins are responsible for several cellular processes like cell proliferation, differentiation and cell survival. This protein can be divided into seven isoforms. ${ }^{42}$ Of these, Stat 3 is the most relevant isoform in cancer cells and thus is widely studied. Malignant progression related to this protein occurs through overexpression of Stat $3 .^{43}$ This process is not regulated by mutations in the Stat proteins but through misregulation of several other proteins including Bcl-xL, ${ }^{44}$ Mcl1, ${ }^{45}$ cyclines, ${ }^{46}$ and c-Myc. ${ }^{47}$ To achieve transcriptional activity, Stat proteins must be phosphorylated at a conserved Tyr residue near the $\mathrm{C}$-terminus to dimerize and bind the DNA. ${ }^{48}$ Herein the phosphorylated amino acid induces the formation of an interaction to the $\mathrm{SH} 2$ domain of the dimerization partner. An in-depth overview of Stat 3 modulators is given in the review by Miklossy and co-authors who focus their publication on Stat proteins and isoforms. ${ }^{49}$ Although we focus on Stat3 here, we want to draw attention to a recent development for Stat5b. Berg and coworkers designed a series of halogen substituted Stafib-1 derivatives, introducing the different halogens in the meta and para position. ${ }^{50}$ This work finally lead to the development of pomstafib-2 (7, Fig. 5), currently the most active and selective inhibitor of Stat5b activation. $^{51}$

LaPorte and coworkers evaluated several triazolothiadiazine inhibitors of phosphorylated Stat3 of which one (8) with an $\mathrm{IC}_{50}$ of $11.4 \pm 10.4 \mu \mathrm{M}$ and a $\mathrm{GI}_{50}$ of $2.2 \pm 0.3 \mu \mathrm{M}$ was later evaluated for its metabolic stability and in vivo effects. ${ }^{52}$ At the maximum single dose administered, $4 \mathrm{mg} \mathrm{kg}^{-1}$, no toxicity in mice was observed. Although very high plasma protein binding was observed $(>99.9 \%)$, the triazolothiadiazine displayed extensive tissue distribution and was able to traverse the blood-brain barrier. ${ }^{53}$ With its antiproliferative effect on phosphorylated Stat3 levels as well as on Stat3 target genes, 8 might qualify as a suitable starting point the development of a potential clinical candidate.

A tetracyclic triterpene (9) isolated from diverse plant families such as Cucurbitaceae proved to abolish Stat3 phosphorylation but was limited in solubility and specificity. ${ }^{54}$ Thus, conjugation with self-associating poly(ethylene oxide)-blockpoly $(\alpha$-carboxylate- $\varepsilon$-caprolactone) (PEO- $b$-PCCL) was able to render this molecule suitable for further studies in cancer immunotherapy. This conjugate maintained its inhibitory activity in B16.F10 melanoma cells ( $\mathrm{IC}_{50} 20 \mu \mathrm{M}$ vs. $10 \mu \mathrm{M}$ for the free drug) and bone marrow-derived dendritic cells (BMDC) in vitro. Furthermore this conjugation led to increased inhibitory activity in immune suppressed BMDCs. ${ }^{55}$ Although this approach proved valuable in terms of bioavailability, the compound is in dire need of optimization. This task will prove quite challenging, given the fact that no mode of action or binding site for the tetracyclic triterpene 9 was described. 
<smiles>COc1ccc(C2=Nn3c(nnc3-c3cc(-c4ccc(Cl)cc4)n[nH]3)SC2C)cc1</smiles>

pomstafib-2

7

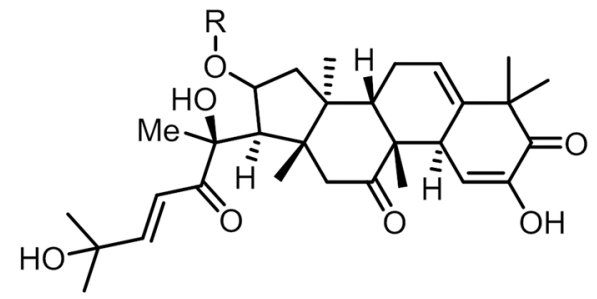

9

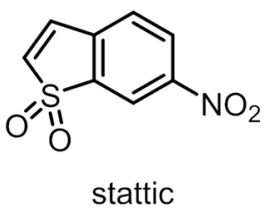

10
8

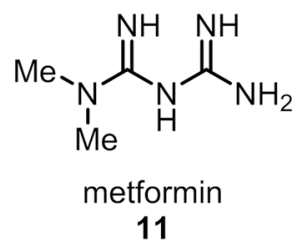

Fig. 5 Chemical structures of modulators of Stat3 activity (9-11).

More than a decade ago Schust and coworkers reported the discovery of stattic (10) as an inhibitor of Stat3 activation and dimerization. ${ }^{56}$ Over the years several articles have been published on this topic aiming for the unveiling of its full potential. Out of these, the work of Leidgens and coworkers represents the most recent approach. Promising results for the treatment of brain tumor-initiating cells and related tumor cells were observed utilizing a combinatorial approach. Applying stattic with the approved drug metformin (11) could give rise to a new strategy for the treatment of high-rate glioma. ${ }^{57}$ Utilizing the synergistic effect of different drugs to improve therapy is an approach to strive for the benefit of patients. In this case, pharmacokinetic parameters, such as the delivery to the brain and dosage, need to be clarified and optimized before this combination therapy can enter phase 1 trials.

\section{Nrf2}

The basic cap'n'collar (CNC) TF Nrf2 (nuclear factor erythroid 2-related factor 2) is a key player in the cellular response to oxidative stress and xenobiotics. Activation of this TF can lead to promising results for the therapy of neurodegenerative diseases like Alzheimer and Parkinson's disease. ${ }^{58}$ Within the last decade, increasing evidence has surfaced revealing the role of Nrf2 in cancer promotion. ${ }^{59}$ Through the activation of Nrf2 cancer cells can achieve higher proliferation rates and acquire chemo- and radioresistance, providing difficulties for therapy. ${ }^{60}$ In this light, it is mandatory for the cell to ensure a tight regulation of this TF. Under homeostatic conditions, Nrf2 is targeted through a ubiquitin ligase complex, including Keap1 (Kelch-like ECH-associated protein
1), for proteasomal degradation. ${ }^{61,62}$ As a part of the cellular response to oxidative stress and oncogenic transformation, Nrf2 is released from this complex, rendering it able to enter the nucleus and activate the transcription of downstream genes. ${ }^{63}$ These include phase II detoxifying enzymes like GST and NQO1. ${ }^{64,65}$ Many small molecules have been reported to modulate Nrf2 activity, wherein Lu and coworkers wrote an excellent review starting from the first approved Nrf2 activator drug Tecfidera and proceeding to the nearly most recent examples of small molecules. ${ }^{66}$ Hence, in the present review, we will focus on two newly reported Nrf2 activators.

A central naphthyl core $(\mathbf{1 2}, \mathbf{1 3})$ for Nrf2 activators has been widely used in various approaches, which led to a series of crystal structures that emphasize the flexibility of Keap1 in the binding area (PDB: 4xmb, Fig. 6). Taking this observation further and making use of the flexible binding site, Yasuda and coworkers extended the substitution pattern on the central core with the intention of gaining selectivity towards the disruption of Keap1:p62. In the best case (14), with a 4-fold improvement in selectivity towards $\mathrm{p} 62$ and $\mathrm{IC}_{50}$ values ranging from $1.5 \mu \mathrm{M}$ to $6.2 \mu \mathrm{M}$ for this series, these molecules could not compete with other naphthyl-based compounds which were as potent as $61 \mathrm{nM} .{ }^{67}$ Nevertheless, driving the development of small molecules interacting with the Kelch domain of Keap1 towards selectivity for certain interaction partners is a much more promising way than general Keap1 binders. The knowledge taken from this approach will shine light upon the understanding of the dynamics of Keap1 and its multiple interaction partners.

Targeting the cap'n'collar bZip domain of Nrf2, Singh and coworkers identified and characterized a polycyclic 
A
B
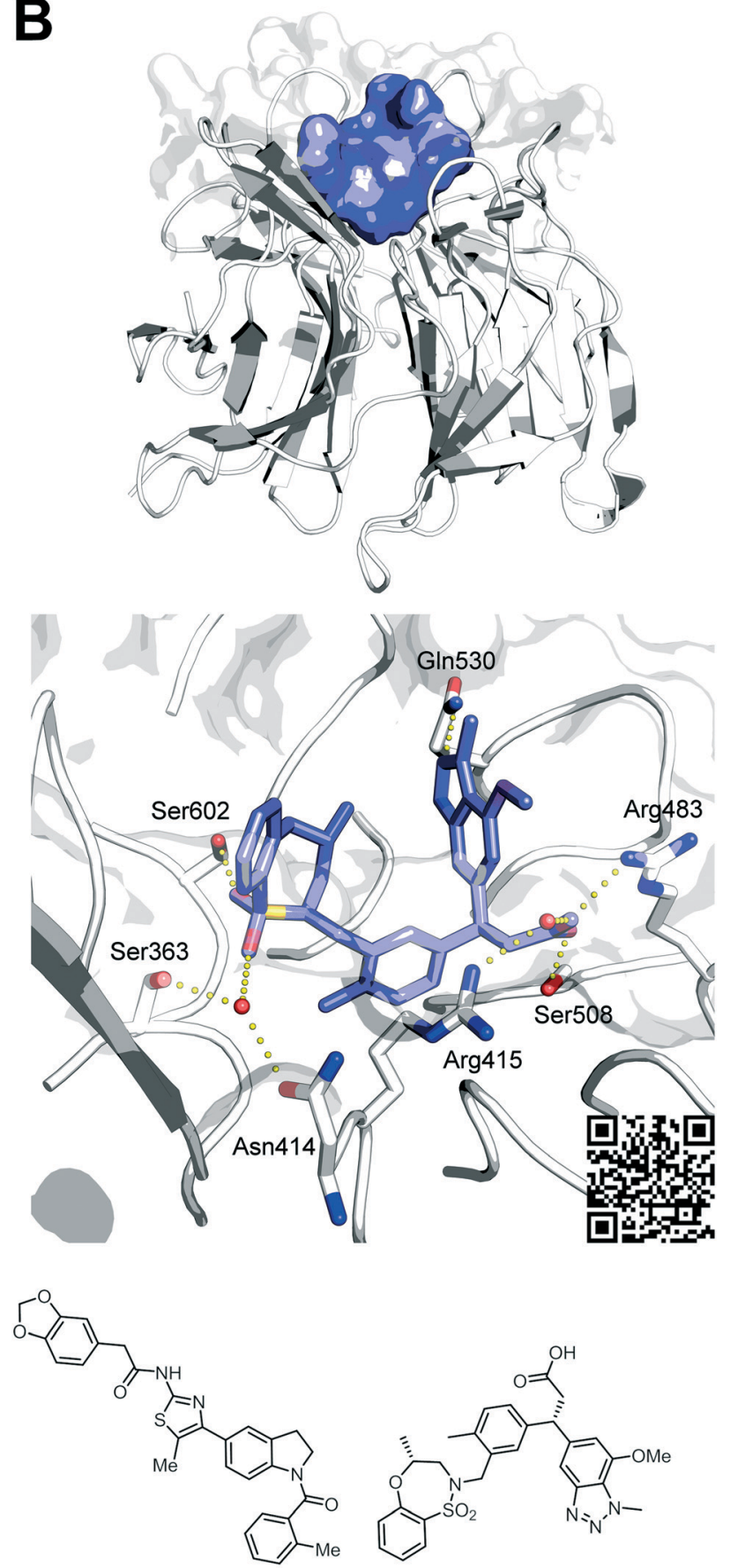

15

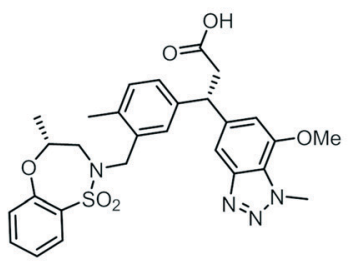

16

Fig. 6 Crystal structure of the Kelch domain of Keap1 in complex with small molecule inhibitors 12 (A, lightblue, PDB 4xmb) and 16 (B, slate, PDB $5 \mathrm{fnu}$ ) of the Nrf2-Keap1 interaction. The ligands occupy the solvent exposed pocket responsible for the regulative function of Keap1 (noninteracting side chains are not shown for clarity purposes). C) Chemical structures of modulators of Nrf2 activity (12-16). The QR codes can be visualized by the app Augment.

compound (15) with a central indole moiety. In various cell-based assays and subsequently in biochemical test systems, the activity of the compound to the binding domain within Nrf2 could be identified. In lung cancer cells which harbor mutated Keap1, this inhibitor could dosedependently decrease the cellular level of Nrf2 and was cytotoxic. Whereas no cytotoxic effect was observed for cell lines deficient of active Nrf2, revealing the inhibitor's selectivity for Nrf2. ${ }^{68}$ Although an effect was observed in the presence of Nrf2 this does not explain the downregulated cellular level of the TF, since binding to the cap'n'collar bZip domain is not known to be associated with low cytoplasmic levels of Nrf2. Compound 15 needs to undergo further critical studies, e.g., the precise determination of the 
binding site at the protein to understand the nature of this observation fully.

A crystallographic screen of more than 300 compounds lead Davies and coworkers to the discovery of three hot spots within the Nrf2 site of Keap1. ${ }^{69}$ Herein the aa Arg483, Tyr525 and Ser602 form important hydrogen bonds to a variety of small fragments. Since the binding affinities for individual fragments was too low, the authors evaluated various combinations of fragments to achieve good activity. The resulting molecule 16 maintained key interactions to the hot-spot areas within the binding pocket and exhibited a good binding affinity of $1.3 \mathrm{nM}$ as determined by ITC. No cytotoxicity could be observed at concentrations of $10 \mu \mathrm{M}$, indicating a suitable profile for a tool compound. In cellular studies molecule 16 could facilitate the translocation of Nrf2 from the cytoplasm to the nucleus. When human primary lung epithelial cells were treated with the molecule an increased level of Nrf2-dependant gene expression was present. Similarly, this effect was observed in disease driven bronchial epithelial cells from COPD patients. Initial in vivo studies revealed the ability to reverse the depletion of GSH after ozone-induced depletion. This data provides a solid base for the use as a chemical probe to further elucidate the Keap1Nrf2 pathway and drive the development of drugs for diseases harboring downregulated Nrf2.

\section{CREB}

The cAMP response element (CRE) binding protein (CREB) is a basic leucine zipper (bZIP) TF that mediates pro-survival, pro-growth, and other stimuli in response to increasing levels of cAMP and $\mathrm{Ca}^{2+} \cdot{ }^{70,71}$ It shares close structural homology and functional features with cAMP response element modulator (CREM) and activating transcription factor-1 (ATF-1), allowing CREB to either homo- or heterodimerize via its bZIP domain. ${ }^{70,72,73}$ Upon stimulation, upstream activating serine/ threonine kinases like protein kinase A (PKA), protein kinase $\mathrm{B}$ (PKB/Akt), mitogen-activated protein kinases (MAPKs) and MAPK-activated protein kinase-1 (MAPKAP-K1/p90 ${ }^{\mathrm{RSK}}$ ) phosphorylate CREB at Ser133 within the kinase-inducible domain (KID), thereby inducing the interaction with the KIDinteraction domain (KIX) of its co-activator CREBBP (CREBbinding protein). ${ }^{74}$ CREBBP acts both as a histone acetyltransferase as well as a scaffold protein to enable the recruitment of the transcriptional machinery. ${ }^{75}$ Additional regulatory sites including Ser142 and Ser143 further enable the specific modulation of the CREB:CBP interaction. ${ }^{76}$

Traditionally, CREB has been known to be involved in learning processes and long-term memory. ${ }^{77}$ More recently, however, CREB has also been identified as a key player in oncogenesis, tumor progression, and metastasis. ${ }^{74}$ Besides its role in solid tumors such as prostate ${ }^{78}$ and non-small cell lung cancer (NSCLC), CREB was also frequently found to be overactivated and/or overexpressed in hematological malignancies, e.g., in acute myeloid leukemia (AML). ${ }^{79,80}$ Furthermore, neurologic disorders are correlated with aberrant CREB signaling. ${ }^{81}$ Although CREB itself is seldom found to be mutated, aberrations of upstream kinases may result in hyperactivation, rendering CREB a proto-oncogene. ${ }^{80}$ Taken together, CREB represents a highly relevant and promising target for therapeutic approaches related to a broad diversity of pathological dysfunctions.

To date, various kinase inhibitors targeting the activating kinases of CREB such as PKB and $\mathrm{p} 90^{\mathrm{RSK}}$ have been developed. ${ }^{74}$ For example, allosteric PKB inhibitors MK-2206 and ARQ092 as well as ATP-competitive PKB inhibitors GDC-0068 and AZD5363 are being investigated in several ongoing clinical studies. ${ }^{82}$ However, the modulation of upstream kinases is not necessarily specific for the targeted $\mathrm{TF}$ and can result in the emergence of resistance and/or bypass mechanisms. ${ }^{80}$

Based on the initial identification of naphthol AS-E phosphate (KG-501, 17, Fig. 7) as a moderately potent inhibitor of the CREB(KID):CBP(KIX) interaction $\left(\mathrm{IC}_{50}=90 \mu \mathrm{M}\right),{ }^{83}$ several derivatives were synthesized and characterized showing the dephosphorylation product naphthol AS-E (18) to be the bioactive compound $\left(\mathrm{IC}_{50}=2.90 \pm 0.81 \mu \mathrm{M}\right)$ as determined by a Renilla luciferase complementation assay. ${ }^{84,85}$ Eventually, optimization of 18 resulted in the development of compound 666-15 (19), exhibiting nanomolar inhibitory potency towards CREB-mediated gene transcription in HEK 293T $\left(\mathrm{IC}_{50}=0.081\right.$ $\pm 0.04 \mu \mathrm{M})$ cells as well as potent anti-proliferative activity against several cancer cell lines in vitro and in vivo. ${ }^{86,87}$ of note, inhibition of CREB-mediated gene transcription by 19 does not appear to solely be caused by its ability to disrupt the CREB:CBP interaction $\left(\mathrm{IC}_{50}=18.27 \pm 1.78 \mu \mathrm{M}\right)$ and thus its mode of action yet remains to be elucidated. ${ }^{86}$ However, these results underscore the great potential of CREB-targeted

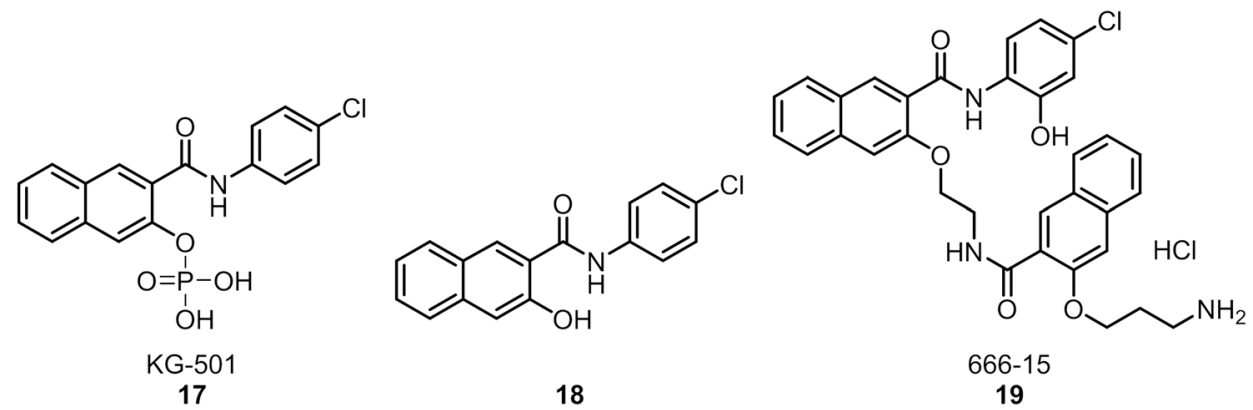

Fig. 7 Chemical structures of modulators of CREB (17-19). 
cancer therapy due to the high tolerability of pharmacological inhibition of CREB. ${ }^{87}$ Together, naphthol AS-E and its more potent derivatives are currently explored as chemical probes in CREB-related pharmacology and pathology thereby fueling the development of novel targeted and drug-like small molecule CREB modulators. ${ }^{88-90}$

\section{ER}

The estrogen receptors $\alpha$ and $\beta$ (ER $\alpha$ and $\operatorname{ER} \beta$ ) are members of the nuclear receptor (NR) superfamily. Because of their ability to bind to DNA and thereby to regulate gene transcription, NRs belong to the class of TFs. ${ }^{91}$ Besides their physiological role in the regulation of the reproductive system, bone metabolism, organ physiology, cardiovascular health, and embryonic differentiation, ${ }^{92}$ ERs have also been demonstrated to be implicated in numerous diseases such as cancer, neurodegenerative and cardiovascular diseases, and osteoporosis. ${ }^{93}$

In addition to the DNA binding domain (DBD) and two distinct domains responsible for activation functions (AF-1/ AF-2), NRs also contain a ligand binding domain (LBD) enabling the sensing of hormonal ligands, ER dimerization, and coregulator recruitment. ${ }^{92,94}$ This LBD offers a prominent way to rationally design drugs based on endogenous ligands in contrast to TFs which do not contain such a domain. Of particular interest is the $\alpha$-helix 12 (H12) within the C-terminal part of the LBD, acting as an indicator of the ligand type that is bound to the ER, namely agonistic or antagonistic ligands that stabilize $\mathrm{H} 12$ in distinct conformations. $^{95,96}$ In the active, agonist-bound conformation, H12 conceals the ligand-binding site by interacting with helices 3 and 11, allowing for the recruitment of coactivators to the AF-2 site, whereas $\mathrm{H} 12$ occupies the AF-2 cleft in the antagonist-bound state, thus preventing coregulator recruitment (Fig. 8). ${ }^{97}$ Moreover, H12 in ER $\alpha$ harbors a mutational hotspot comprising residues Leu536, Tyr537, and Asp538 that are frequently mutated in hormone-resistant metastatic breast cancer. ${ }^{98,99}$ Replacement of leucine at position 536 by serine was demonstrated to stabilize the canonical inactive conformation of $\mathrm{ER} \alpha$ without affecting binding of raloxifene. ${ }^{100}$ In contrast, Y537S and D538G mutations within ER $\alpha$ mediate anti-estrogen resistance by altering the conformational dynamics of helices 11 and 12 and thus stabilizing the active agonist state. These altered dynamics lower the binding affinities for both agonists and antagonists and enable hormone-independent coactivator recruitment. ${ }^{97}$

Due to the immediate relevance of estrogen signaling in pathophysiological processes, numerous small molecule modulators have been developed and approved by the FDA for the treatment of a broad diversity of diseases. Generally, these ligands are divided into: i) compounds with agonistic features in all tissues (full agonists), e.g., estradiol; ii) ligands that exhibit antagonistic effects in all tissues and induce protein degradation (pure antagonists, selective ER downregulators (SERDs)), e.g., fulvestrant; iii) molecules with a mixed agonistic/antagonistic mode of action (selective ER modulators, SERMs) depending on the ER isoform selectivity, tissuespecific expression of ER isoforms and coregulators, and ligand-induced conformational changes and dimerization behavior, e.g., tamoxifen. Interestingly, tamoxifen has also been found to support adverse effects including carcinogenesis in endometrial tissue. However, it is suggested that the genotoxic properties arise from the generation of $\alpha$-hydroxylated tamoxifen metabolites rather than from its partial estrogen-agonist features. ${ }^{101,102}$ To circumvent side effects and overcome suboptimal pharmacokinetic properties as observed for fulvestrant as well as treatment- and mutation-induced resistant breast cancers, drug discovery campaigns currently focus on the development of substances with optimized tissue specificity, oral bioavailability, and potency. To date, only a limited number of compounds fulfilling the aforementioned criteria have been reported such as elacestrant (RAD-1901, ER-306323, 20) ${ }^{103}$ brilanestrant (GDC0810, ARN-810, RG-6046, RO-7056118, 21), ${ }^{104}$ and AZD9496 (22) ${ }^{105,106}$ all of which belong to the group of SERDs. Moreover, such SERDs provide valid tools to overcome resistances emerging from mutations and/or prolonged treatment with tamoxifen or aromatase inhibitors. ${ }^{107}$ Additionally, it has been shown that combinations of SERDs and the CDK4/6 inhibitor palbociclib hold the potential to effectively target endocrine therapy-resistant and mutant ER-expressing breast tumors. ${ }^{108,109}$

\section{AR}

Also, being a member of the NR superfamily and more specifically of the steroid receptor subfamily, the androgen receptor (AR) shares several structural features, including a DBD and LBD, with the ERs $\alpha$ and $\beta$ as well as with the other members, i.e., the glucocorticoid receptor (GR), the mineralocorticoid receptor (MR), and the progesterone receptor (PR). ${ }^{110,111}$ Its major endogenous ligands are testosterone and the metabolite $5 \alpha$-dihydrotestosterone (DHT) that mediate AR homodimerization, coactivator binding, and transcription of androgen response element (ARE) regulated genes. ${ }^{112,113}$ The AR is critical for the development and regulation of male and female reproductive organs and their physiology as well as in male sexual differentiation, male puberty changes, prostate growth and spermatogenesis in adults. ${ }^{114,115}$ Conversely, AR dysregulation is associated diverse pathologies including androgen insensitivity syndromes (AIS), spinal bulbar muscular atrophy (SBMA), benign prostatic hyperplasia, prostate cancer, and osteoporosis. ${ }^{116-119}$ Thus depending on the desired purpose either agonistic or antagonistic properties of AR modulators can be preferred. For example, impaired AR function might be restored upon androgen therapy, whereas androgen receptor antagonists have proven to be valuable tools in prostate cancer therapy. ${ }^{120}$

Originally, steroidal ligands derived from natural androgens have been characterized and evaluated for the treatment of, e.g., osteoporosis in postmenopausal women, chronic 

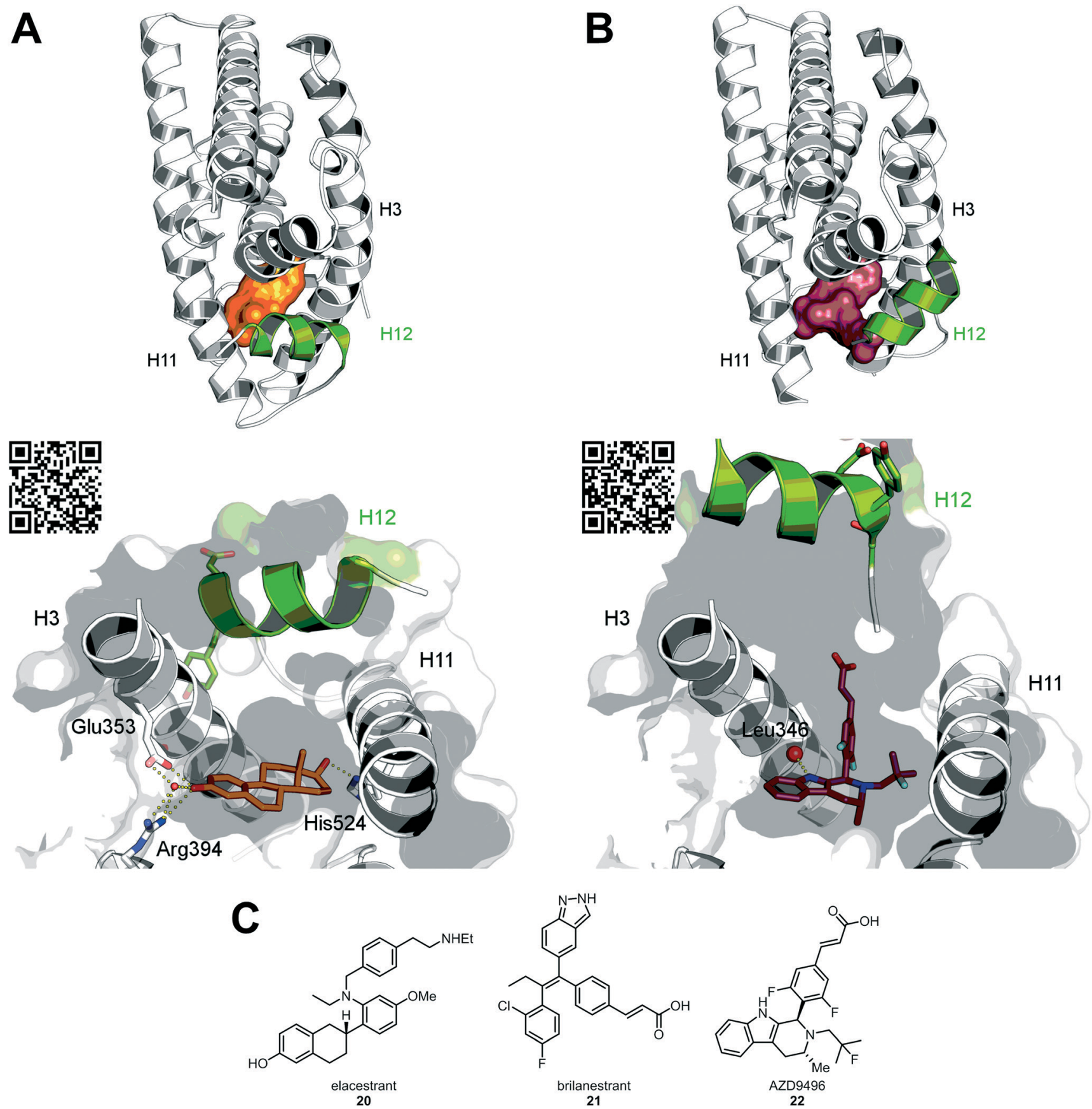

Fig. 8 Crystal structures of the ligand-binding domain (LBD) of the estrogen receptor $\alpha(E R \alpha)$ in complex with full agonist estradiol (A, orange, PDB 1ere) and with the selective ER downregulator AZD9496 (B, 22, dark red, PDB 5acc). Depending on the type of ligand bound to the LBD, helix 12 (green) adopts specific conformations (non-interacting side chains are not shown for clarity purposes). C) Chemical structures of modulators of ER activity (20-22). The QR codes can be visualized by the app Augment.

wasting conditions, and prostate cancer. ${ }^{121-123}$ However, significant adverse effects such as hepatotoxicity and off-target mediated side effects in combination with the successful development of SERMs initiated the development of selective androgen receptor modulators (SARMs) of nonsteroidal origin such as first-generation SARM bicalutamide (23) and second generation SARMs enzalutamide (24) and apalutamide (25) exhibiting favorable pharmacokinetics, tissue-selectivity, and reduced side effects..$^{115,124,125}$
However, numerous mutations in the AR were demonstrated to mediate resistance to first and second generation inhibitors, relaxation of AR ligand specificity, altered coregulator binding, and dysregulated AR homodimerization behavior. $^{126-129}$ The majority of these genetic alterations occur within the LBD of the AR with the hotspot regions 671679, 702-731, 742-764, and 873-911 (numbering according to the revised sequence of full-length human AR, UniProt entry P10275). ${ }^{128,130,131}$ Prominent examples of mutation- 
induced alteration of ligand specificity are the T878A point mutation enabling AR activation by progesterone and estradiol as well as $\mathrm{W} 742 \mathrm{~L}$ resulting in the resistance towards thiohydantoins enzalutamide (24) and apalutamide (25). ${ }^{129,132}$

As can be deduced from the crystal structures of $\mathrm{AR}^{\mathrm{wt}}$ in complex with testosterone and $\mathrm{AR}^{\mathrm{W} 742 \mathrm{~L}}$ in complex with $(R)$ bicalutamide, the substitution of the bulky indole side chain of tryptophan by the smaller side chain of leucine at position 742 enables the accommodation of (R)-bicalutamide (23) without displacing helix $\mathrm{H} 12$ from the agonist-bound conformation thereby enabling coactivator binding and downstream signaling (Fig. 9). ${ }^{133,134}$ Furthermore, thiohydantoins 24 and 25 exhibit undesired agonistic activity on mutant $\mathrm{AR}^{\mathrm{F877L}} \cdot{ }^{135,136}$ The recently developed next-generation SARM darolutamide (ORM-201, 26) exhibits beneficial, antagonistic effects on several AR mutants and superior efficacy compared to 24 and 25 and is currently under clinical investigation for the treatment of metastatic castration-resistant prostate cancer. ${ }^{137}$

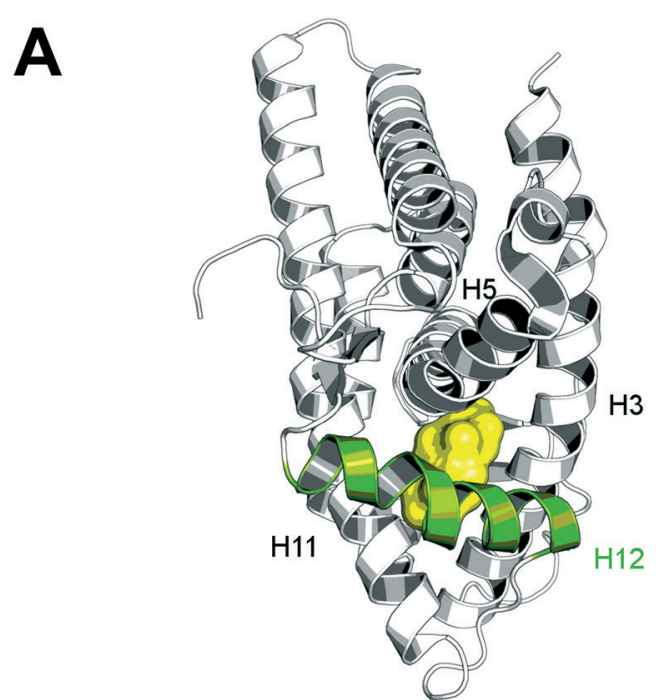

B
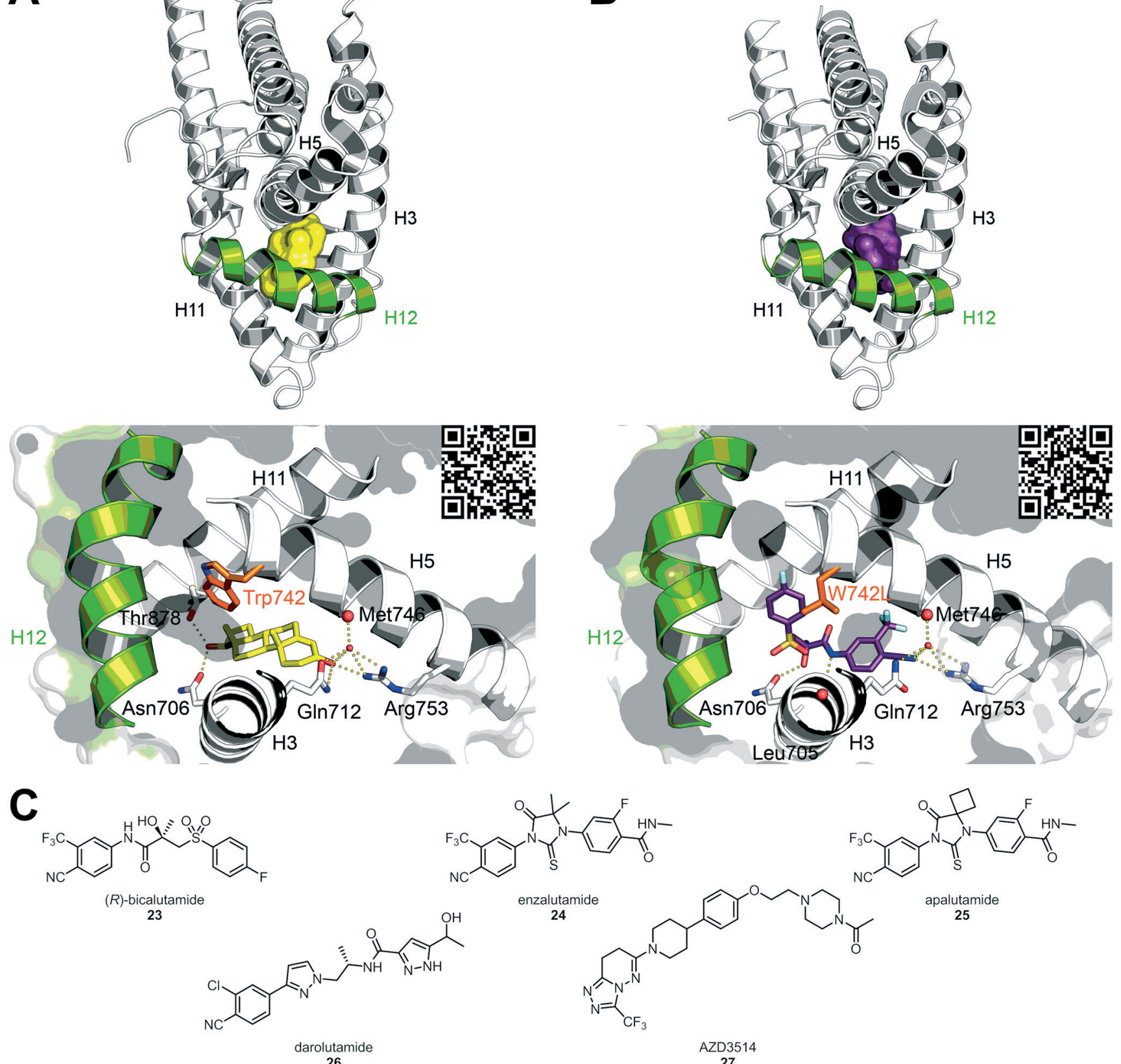

24<smiles>FC(F)(F)c1nnc2n1N=C(N1CCC(c3ccccc3)CC1)CC2</smiles>
25

Fig. 9 Crystal structures of the ligand-binding domain (LBD) of the androgen receptor in complex with testosterone (A, yellow, PDB 2am9) and with the SARM $(R)$-bicalutamide (B, 23, purple, PDB 1z95). The point mutation W742L allows for bicalutamide to bind to the activated conformation of AR and pre-orients helix $\mathrm{H} 12$ (green) for coactivator protein binding (non-interacting side chains are not shown for clarity purposes). C) Chemical structures of modulators of AR activity (23-27). The QR codes can be visualized by the app Augment. 
Driven by the discovery of SERDs, experimental ligands aiming at the downregulation of the AR have been reported recently and resulted in the development of optimized selective AR downregulator (SARD) AZD3514 (27). ${ }^{138,139}$ Although AZD3514 exhibited promising efficacy in phase I trials, its development was terminated due to tolerability issues. ${ }^{140,141}$ Moreover, the concept of PROTACs has also been successfully applied for the AR, demonstrating the considerable potential of SARDs in the treatment of prostate cancer. ${ }^{142,143}$

An alternative strategy for targeting mutant AR is represented by N-terminal domain (NTD) antiandrogens, binding remote of the LBD and thereby preventing coregulator recruitment and subsequent AR-regulated gene transcription. ${ }^{144,145}$ The major advantage of this type of inhibitors might base on the ability to bind the AR irrespective of its mutation status and splice variants that often confer resistance towards LBD targeting inhibitors. ${ }^{146}$

\section{HIF}

Hypoxia-inducible factors (HIFs) are heterodimeric, basic helix-loop-helix (bHLH)-PER ARNT SIM (PAS) TFs comprising an oxygen-regulated $\alpha$ - and a stable $\beta$-subunit. ${ }^{147,148}$ These TFs orchestrate cellular adaptation mechanisms in response to hypoxia such as erythropoiesis, angiogenesis, and metabolism, ${ }^{149}$ but can also be regulated by growth factors, hormones, and cytokines under normoxic conditions. ${ }^{150}$

Upon bHLH/PAS-mediated dimerization of either HIF-1 $\alpha$, HIF- $2 \alpha$, or HIF-3 $\alpha$ with HIF-1 $\beta$ (ARNT, arylhydrocarbon receptor-nuclear translocator), the primarily represented $\beta$-subunit, ${ }^{151}$ the protein complex translocates into the nucleus and binds to the hypoxia-response element (HRE) with the core sequence A/GCGTG. ${ }^{152}$ HIF- $1 \alpha$ and HIF- $2 \alpha$ are generally considered to act as transcriptional activators and have numerous structural and functional features in common including two nuclear localization signals (NLSs), bHLH and PAS domains, an oxygen-dependent degradation (ODD) domain, and a N-terminal as well as a C-terminal transactivation domain (TAD). ${ }^{153}$ However, they also differ in tissue-specific expression, target genes, and involvement in carcinogenesis. $^{151}$ In contrast, the less studied HIF-3 $\alpha$ subunit lacks the C-terminal TAD and only comprises a single NLS and was demonstrated to predominantly be a negative regulator of hypoxia-inducible gene expression. ${ }^{154}$

Regulation of HIF-1 activity is achieved via posttranslational modification of HIF- $1 \alpha$ by oxygen-dependent hydroxylation of prolines 402 and 564 within the ODD domains, a process catalyzed by several prolyl-4-hydroxylases (PHD1-3/ EGLN1-3). ${ }^{153}$ These hydroxylated prolines enable the von Hippel Lindau tumor suppressor protein (pVHL) to bind and initiate ubiquitin-mediated proteasomal degradation of HIF-1 $\alpha{ }^{155}$ Moreover, hydroxylation at Asn803 within the C-terminal TAD of HIF- $1 \alpha$ by factor inhibiting HIF (FIH) prevents coactivator proteins CREBBP and p300 from binding and thereby downregulating transcription. ${ }^{156}$ In addition, HIF-1 $\alpha$ stability, nuclear localization, and transcriptional activity is regulated by a plethora of individual phosphorylations mediated by diverse kinases such as ERK1/2, PKA, and GSK3 $\beta .{ }^{151}$ HIF-1 was found to play a pivotal role in tumor adaptation to hypoxia, a hallmark feature of the tumor microenvironment, ${ }^{157}$ and HIF-1 overexpression and hyperactivation have been linked to increased resistance to radio- and chemotherapy. ${ }^{158}$ Due to its complex regulatory nature, numerous target points to modulate HIF-mediated signaling are addressable: HIF- $\alpha:$ HIF- $\beta$ dimerization, HIF- $\alpha$ :pVHL interaction, HIF- $\alpha: C R E B B P / p 300$ interaction, and HIF:DNA interaction as well as the interactions between HIF and its modifying enzymes PHD1-3 and FIH. ${ }^{159}$ Crystallographic data published by $\mathrm{Wu}$ et al. revealed a total of five distinct pockets within the HIF:ARNT complex potentially addressable by small molecules, thus allowing the rational design of modulators and targeting of HIF in a variety of diseases. ${ }^{160}$ Recently, HIF- $2 \alpha$ PAS-B domain-selective inhibitors 28 and PT2399 (29) have been described that allosterically inhibit HIF-2 heterodimerization and DNA binding in vitro (Fig. 10). ${ }^{161,162}$ Due to their selectivity for HIF-2, modulators of this type might provide a novel approach to target HIF-2 driven diseases, e.g., renal cell carcinoma and kidney cancer. ${ }^{161-163}$ Promising approaches in modulating HIF activity have been developed by addressing its modifying enzymes, PHD1-3. HIF prolyl hydroxylase inhibitors have recently been reviewed extensively by Chan et al., ${ }^{164}$ highlighting numerous small molecules, e.g., molidustat (30), ${ }^{165}$ roxadustat $(31),{ }^{166}$ and daprodustat (32), ${ }^{167}$ currently under investigation in pre-clinical and clinical studies for the treatment of anemia, ischemia, and inflammation. In contrast, only a few inhibitors of FIH have been reported to date. ${ }^{168}$ However, recent studies have revealed that some HIF target genes are more dependent on the inhibition of FIH-catalyzed hydroxylation of Asn803 than are others, underscoring a more context-specific role of $\mathrm{FIH}$ in contrast to PHDs. ${ }^{168}$

Besides the inhibition of HIF hydroxylases, considerable efforts have been devoted towards the identification of protein-protein interaction inhibitors of the HIF:CREBBP/p300 and the HIF:pVHL complexes. In 2011, the groups of Wang and van Meir reported the identification of arylsulfonamide KCN1 (33) and derivatives as potent inhibitors of the HIF-1: CREBBP/p300 interaction with anti-tumorigenic efficacy in vivo by inhibiting HIF-1:CREBBP/p300 complex formation. ${ }^{169-171}$ In 2012, hydroxyproline-based ligands of pVHL with low micromolar affinity were reported to be inhibitors of the HIF-1 $\alpha$ :pVHL complex. ${ }^{172}$ Subsequent structureguided medicinal chemistry optimization yielded inhibitors with nanomolar affinities. ${ }^{173}$ Recently, optimized compound VH298 (34) was characterized in cells and demonstrated to be non-toxic, to stabilize and induce accumulation of HIF1- $\alpha$ and HIF2- $\alpha$, and to upregulate HIF-dependent target gene expression serving as a novel chemical probe of the HIF signaling cascade. ${ }^{174}$ In contrast to preventing ubiquitin-mediated proteasomal degradation, proteolysis targeting chimeras (PROTACs) recruit target proteins to an E3 ubiquitin ligase, e.g., pVHL, thereby inducing their downregulation. The 

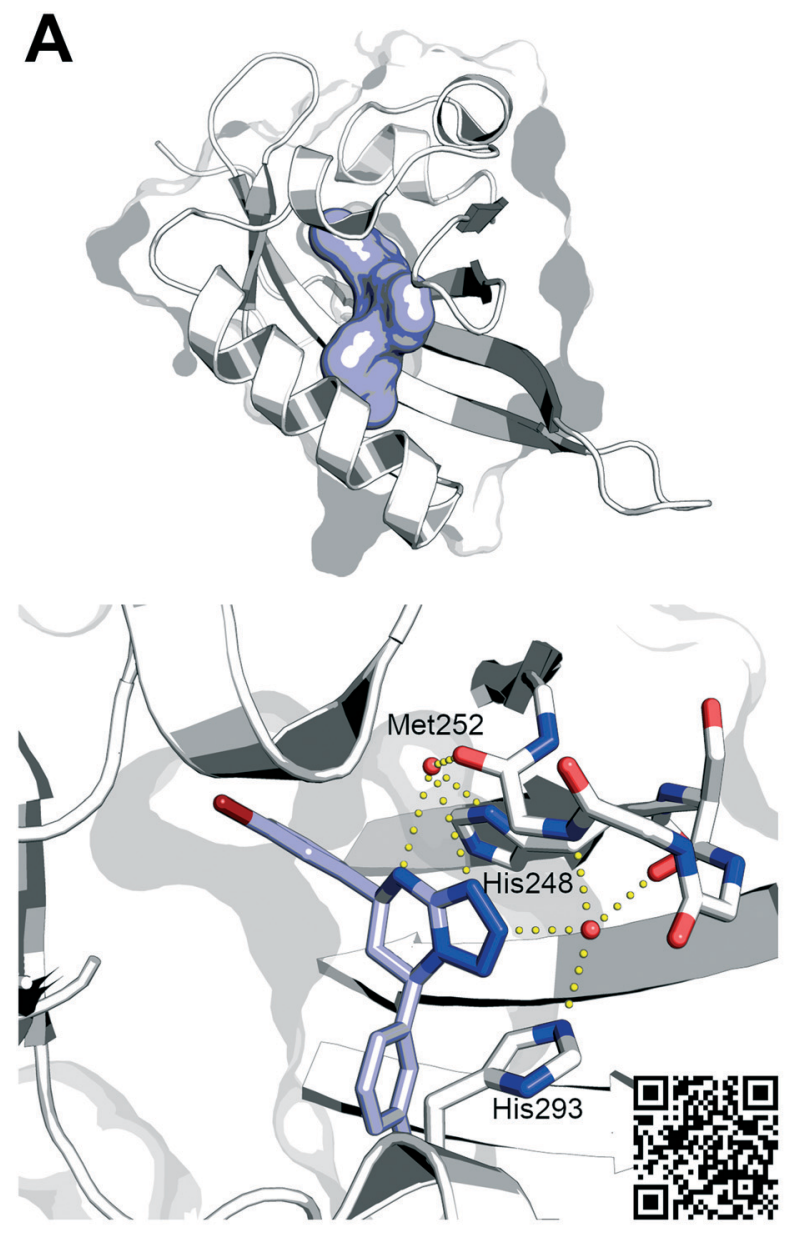<smiles>Brc1cccc(C2CC(c3cccc(Br)c3)n3nnnc3N2)c1</smiles>

28<smiles>O=C(O)CNC(=O)C1C(=O)N(C2CCCCC2)C(=O)N(C2CCCCC2)C1=O</smiles><smiles>N#Cc1cc(F)cc(Oc2ccc(S(=O)(=O)C(F)F)c3c2CC(F)(F)C3O)c1</smiles>

29
B
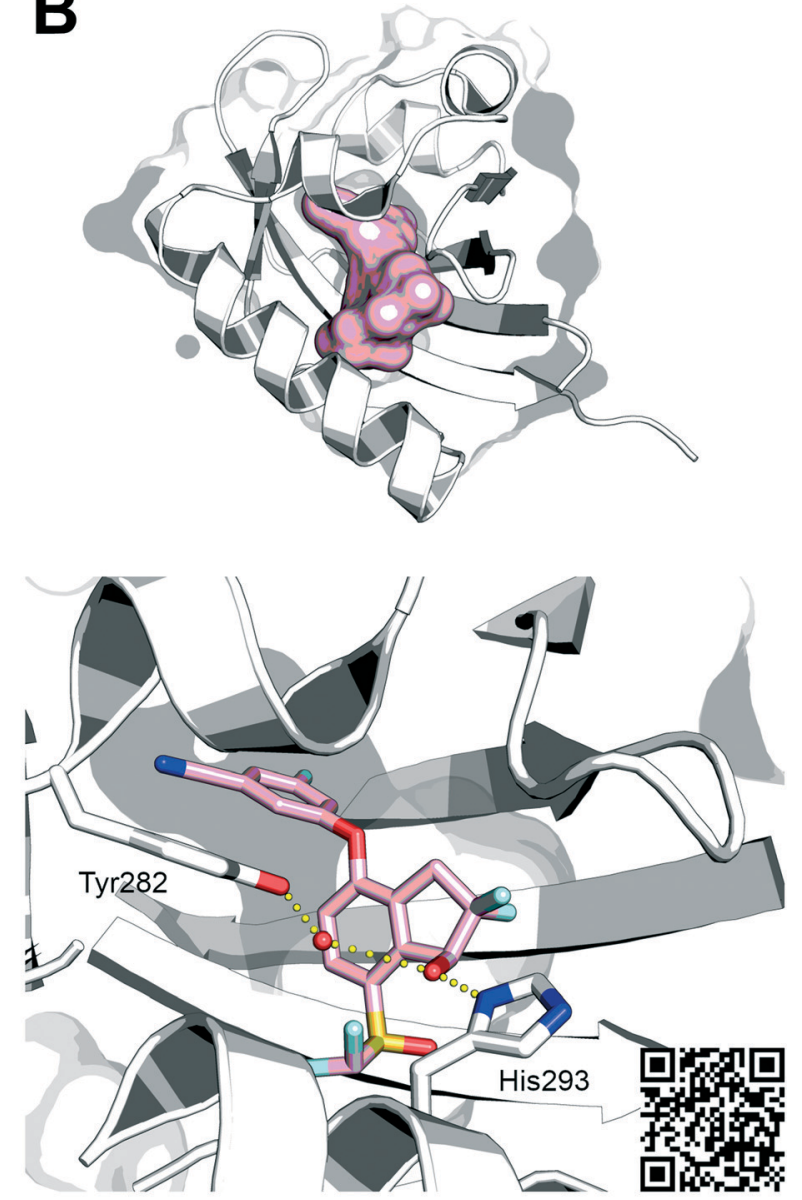<smiles>O=C(O)CNC(=O)c1nc([N+](=O)[O-])c2cc(Oc3ccccc3)ccc2c1O</smiles>
31 30<smiles>Cc1ncsc1-c1ccc(CNC(=O)C2C[C@@H](O)CN2C(=O)C(NC(=O)C2(C#N)CC2)C(C)(C)C)cc1</smiles>

Fig. 10 Crystal structures of allosteric HIF-2 $\alpha$ inhibitors 28 (A, lightblue, PDB 4xt2) and 29 (B, light pink, PDB 5ufp) in complex with the HIF-2 $\alpha$ PAS-B domain. Both inhibitors occupy the identical binding pocket thereby preventing HIF-2 heterodimerization (non-interacting side chains are not shown for clarity purposes). C) Chemical structures of modulators of HIF-2 $\alpha$ PAS-B domain (28-29), HIF prolyl hydroxylases (30-32), HIF-1: CREBBP/p300 complex (33), and HIF-1 2 :pVHL complex (34). The QR codes can be visualized by the app Augment.

potentials and limitations of this approach have recently been reviewed by Bondeson et al. ${ }^{175}$

\section{$N F-\kappa B$}

TFs of the nuclear factor kappa-light-chain-enhancer of activated B cells (NF- $\mathrm{\kappa} B$ ) family are key regulators of immune and inflammatory processes in response to environmental, mechanical, chemical, and microbiological stresses, ${ }^{176}$ and have emerged as central players in cancer development, progression, and metastasis. ${ }^{177,178}$ The mammalian NF-kB/Rel protein family comprises five distinct members: RelA (p65), RelB, c-Rel, and NF-KB1 (p105) and NF-אB2 (p100), the latter two being precursor proteins of p50 and p52, respectively. ${ }^{176}$ 
All family members share an N-terminal Rel homology domain (RHD), ${ }^{179}$ enabling DNA-binding through homo- as well as heterodimerization. ${ }^{180}$ However, only p65, RelB, and c-Rel share C-terminal transactivation domains (TAD), whereas p105 and p100 have long C-terminal ankyrin repeatcontaining domains (ARDs) that are proteolytically removed to yield mature p50 and p52, respectively. ${ }^{181}$ Only in the presence of a TAD are NF- $\kappa \mathrm{B}$ dimers able to positively regulate target gene transcription; homo- or heterodimers of p50 and p52 lack this ability and can instead negatively regulate transcription. ${ }^{182}$

In unstimulated cells, NF- $\mathrm{B}$ dimers are commonly bound to members of the inhibitors of the $\kappa \mathrm{B}(\mathrm{I} \kappa \mathrm{B})$ family, including p105 and p100. ${ }^{183}$ These protein complexes are formed by interaction of ARDs with DNA-binding domains thereby retaining the transcription factor's cytosolic localization and rendering them transcriptionally inactive. ${ }^{184}$ In the canonical pathway, upon stimulation with, e.g., lipopolysaccharides (LPS), tumor necrosis factor $\alpha$ (TNF $\alpha)$, or interleukin-1 (IL-1), I $\mathrm{B}$ kinase (IKK) become activated and in turn phosphorylate two serine residues within $\mathrm{I} \kappa \mathrm{B}$, thereby tagging $\mathrm{I} \kappa \mathrm{B}$ for ubiquitination and subsequent proteasomal degradation. Uncomplexed NF- $\mathrm{NB}$ dimers are then able to translocate to the nucleus and initiate transcription of target genes. ${ }^{184}$ Alternatively, in the non-canonical pathway, activation of the B-cell activation factor receptor (BAFF-R), CD40, lymphotoxin $\beta$-receptor (LT $\beta \mathrm{R})$, or receptor activator of nuclear factor kappa-B ligand (RANKL) results in the activation of IKK $\alpha$ by NF- $\kappa B$-inducing kinase (NIK). ${ }^{185,186}$ Active IKK $\alpha$ then phosphorylates p100, again targeting it for ubiquitin-dependent proteasomal degradation to yield mature p52 and to allow dimerization with RelB and subsequent nuclear translocation. ${ }^{187}$ Furthermore, fine-tuning of NF- $\kappa \mathrm{B}$ transcriptional activity occurs via a multitude of post-translational modifications including phosphorylation, acetylation, and ubiquitination. ${ }^{188}$
Besides its major role in regulating physiological processes, aberrant NF- $\kappa \mathrm{B}$ signaling caused by genetic lesions within genes encoding either NF- $\mathrm{BB}$ or its regulating enzymes is frequently observed in numerous types of cancer. ${ }^{189}$ Furthermore, NF- $\kappa$ B-dependent production of tumor-promoting cytokines by immune or inflammatory cells can also foster malignant transformation. ${ }^{190}$ To date, numerous NF-אB pathway modulators of both natural and synthetic origin have been identified that act on diverse levels of NF-кB-related signaling such as upstream of IKK, IKK activity and IкB phosphorylation, I $\mathrm{B}$ degradation, nuclear translocation of $\mathrm{NF}-\kappa \mathrm{B}$, DNA-binding of NF- $\kappa \mathrm{B}$, and NF- $\kappa \mathrm{B}$ transactivation. ${ }^{191,192}$ However, to date, few selective modulators - especially small molecules - of the NF- $\mathrm{B}$ pathway have been identified and characterized. Because of a lack of target-, pathway- and tumor cell-specificity, attempts to develop such inhibitors have resulted in adverse effects. IMD-0354 (35, Fig. 11), an inhibitor of IKK $\beta$, has been shown to block I $\mathrm{B} \alpha$ phosphorylation, thereby preventing $\mathrm{NF}-\kappa \mathrm{B}$ release and nuclear translocation. ${ }^{193}$ Its anti-proliferative efficacy has been demonstrated in human mast cells harboring hyperactivated c-Kit and in cellular models of chronic lymphocytic leukemia (CLL). Furthermore, combination therapy approaches consisting of IMD-0354 (35) and doxorubicin proved to be efficacious in overcoming multidrug resistance in murine models. ${ }^{194}$ In contrast, proteasome inhibitors such as bortezomib (36), carfilzomib (37), and ixazomib (38) appear to have diverse ef-

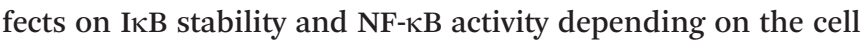
and disease type. In several multiple myeloma cell lines, bortezomib induced the unexpected down-regulation of IкB $\alpha$ resulting in the activation of NF- $\kappa \mathrm{B} .{ }^{195}$ Conversely, Juvekar et al. reported the nuclear accumulation of $\mathrm{I} \kappa \mathrm{B} \alpha$ associated with I $\kappa \mathrm{B} \alpha$-mediated inhibition of NF- $\kappa \mathrm{B}$ DNA binding activity upon proteasome inhibitor treatment. ${ }^{196}$ Moreover, NF- $\kappa \mathrm{B}$ inhibition was demonstrated to be specific for antiapoptotic<smiles></smiles>

35

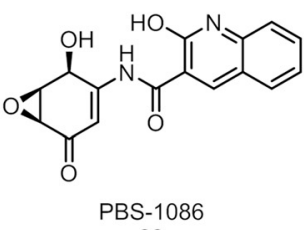

39<smiles>CC(C)C[C@H](NC(=O)C(Cc1ccccc1)NC(=O)c1cnccn1)B(O)O</smiles>

36

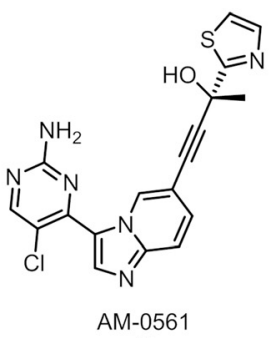

40
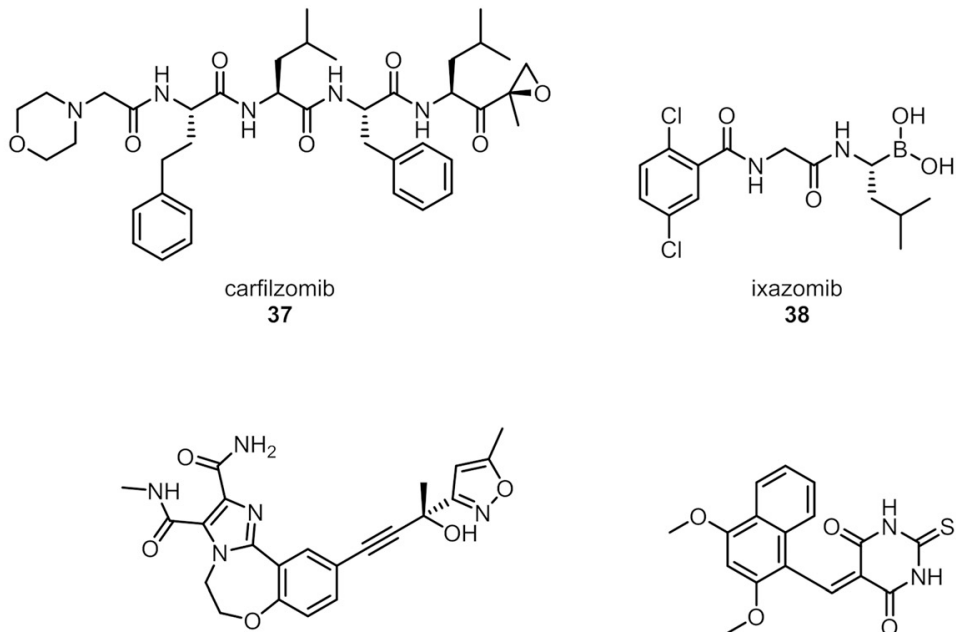

41

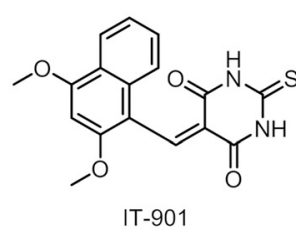

42

Fig. 11 Chemical structures of modulators of NF-кB activity, i.e. IKK $\beta$ inhibitor (35), proteasome inhibitors (36-38), covalent Rel protein inhibitor (39), NIK inhibitors (40-41), and C-Rel inhibitor (42). 
genes thus indicating a preference for I $\mathrm{I} B \alpha$-triggered inhibition of p65/p50 heterodimer-mediated gene transcription compared to p50/p50 homodimers. ${ }^{196}$ These findings illustrate the need for in-depth cell type-specific studies to unravel the molecular contexts of the $\mathrm{NF}-\kappa \mathrm{B}$ pathway and disease pathology to allow for a precise and targeted therapeutic intervention. Ultimately, proteasome inhibitors are known to severely affect cellular proteostasis thereby inducing proteotoxic stress. Thus, the anti-tumor activity of such drugs is improbable to be solely attributed to inhibition of NF- $\kappa \mathrm{B}$ signaling. ${ }^{197}$ PBS-1086 (39), a covalent inhibitor of NF- $\kappa \mathrm{B}$, inhibited DNA binding of Rel proteins by irreversibly binding to p65, RelB, and c-Rel. ${ }^{198}$ Its efficacy was demonstrated in multiple myeloma xenografts and, additionally, synergistic effects were observed for co-treatment with bortezomib in bortezomib-resistant multiple myeloma cell. ${ }^{198}$ Moreover, Blakely and coworkers investigated the role of $\mathrm{NF}-\kappa \mathrm{B}$ in the resistance of NSCLC cell lines towards epidermal growth factor receptor (EGFR) tyrosine kinase inhibitor (TKI) treatment. They found that NF- $\kappa \mathrm{B}$ hyperactivation in response to EGFR oncogene inhibition may drive tumor cell survival that can be overcome by PBS-1086-induced inhibition of $\mathrm{NF}-\kappa \mathrm{B}$, thus characterizing a novel therapeutic approach in targeting EGFR-driven NSCLC. ${ }^{199}$ An alternative strategy to target myeloma cells that are dependent on the NIK-driven, noncanonical NF- $\kappa \mathrm{B}$ pathway was described by Demchenko et al. in 2014. ${ }^{200}$ Inhibition of NIK with AM-0561 (40) $\left(K_{\mathrm{i}}=0.3 \mathrm{nM}\right)$ was shown to potently kill multiple myeloma cell lines harboring NIK-activating mutations ( $\left.\mathrm{IC}_{50} 1-3 \mu \mathrm{M}\right)$. Moreover, cotreatment with IKK $\beta$ inhibitors or dexamethasone enhanced the anti-proliferative effects in cellular models of multiple myeloma. In 2017, Castanedo et al. published a series of small molecule inhibitors of NIK with high selectivity over PI3K $\delta$ that show subnanomolar affinity towards NIK and selective inhibition of nuclear translocation of p52 over RelA. Medicinal chemistry optimization yielded benzoxepin 41 with favorable in vivo PK properties thus providing a powerful new tool for studying the pharmacology of inhibiting noncanonical, p52-mediated NF- $\kappa$ B signaling. ${ }^{201}$ Furthermore, a recent study published by Shono et al. revealed the promising therapeutic potential of IT-901 (42), a naphthalenethiobarbiturate-based inhibitor of c-Rel, towards hematological malignancies in vivo without affecting the antitumor and antiviral activity of T-cells by inhibiting DNA binding of c-Rel.$^{202,203}$

\section{BET proteins}

As transcriptional regulators BET proteins can be found in animals, plants, and fungi. These proteins comprise an $\mathrm{N}$-terminal bromodomain which interacts with acetylated lysine residues on histone tails, thus regulating the transcription of various proteins and the cell cycle. BET proteins are widely known to be overexpressed in multiple tumor types. ${ }^{204}$ This mammalian protein family consists of the four members $\operatorname{Brd} 2, \operatorname{Brd} 3, \operatorname{Brd} 4$ and BrdT. ${ }^{205}$ Herein Brd4 seems to be the most relevant in cancer cells. While Brd4 usually contributes directly to cancer cell progression, in NUT midline carcinoma, it acts as the oncogenic driver when it fuses with the nuclear protein in testis (NUT). During the cell cycle, Brd4 acts as mitotic bookmark for the genes which should be transcribed in late mitosis and early G1. This is possible since Brd4 is one of the few proteins that remain bound to the chromosomes during mitosis.

Having this in mind it seems hardly possible to target a specific TF through BET inhibition. Several reports have elucidated this assumption and found it to be partially true. Since Brd 4 binds to superenhancers, which are regulators of genes that determine the cells identity, it is possible to gain selectivity for cancer cells over healthy cells. ${ }^{206-209}$ Looking closer into this observation the utilizing of the Brd4 inhibitor JQ1 (43) reveals an impact on Myc transcription. ${ }^{210-212}$ This was confirmed by the observation of downregulated Myc mRNA levels. ${ }^{213}$ However this is not the complete story, since in a high throughput pharmacogenomics screen of JQ1 in 673 cell lines, 99 were sensitive towards the drug, while only 4 of them had amplified Myc levels. ${ }^{214}$ Further studies need to be conducted to fuel the understanding of Brd4 inhibition and its effect on the cells. It has to be critically evaluated if the activity which is observed in cells is the result of BET inhibition or a more general reaction towards the molecule. A more promising approach for the clinical use is represented in combinatorial approaches with approved drugs to achieve a synergistic effect. Doroshow and coworkers recently published a state of the art review highlighting the many in vivo studies and clinical trials on the topic of BET inhibitors. ${ }^{204}$ In this review we will highlight the newest reports in the field of BET inhibitors.

Mimicking acetylated lysine for the targeting of bromodomains is a promising way which Sharp and coworkers went with the design of their compounds. They build their focused small molecule library through a five-step synthesis. The most potent triazolobenzodiazepines $(44,45)$ had an $\mathrm{IC}_{50}$ of $6 \mathrm{nM}$ and $2 \mathrm{nM}$ on Brd4, respectively as determined by AlphaScreen. Compound $\mathbf{4 4}$ was successfully co-crystallized with the related protein Brd2 confirming the acetyl-lysine mimetic nature of these small molecules (PDB 5u6v). Comparison with the crystal structure of JQ1 (43) in complex with Brd4 revealed a similar binding mode for both compounds (Fig. 12). ${ }^{215}$ Cellular evaluation revealed a comparable activity profile for both compounds with $\mathrm{EC}_{50}$ values ranging from 70 to $1000 \mathrm{nM}$ for different cancer cell lines as determined by Cell-TiterGlo. ${ }^{216}$ As for the previously reported BET inhibitors it is mandatory to carefully evaluate the activity profile on the different TFs and exclude effects based on unspecific binding.

Next to the modulation of Myc through bromodomains, addressing CREBBP, comprising such a reader domain of acetyl lysine residues, has gained interest within the last years. Prominent examples are the tetrahydro-pyrazolopyridine GNE-272 (46), which showed in vitro activity in FRET assays of $0.02 \mu \mathrm{M}$ and retained a good balance of cell potency, selectivity and favorable in vivo PK. ${ }^{217}$ Another example is the benzoxazepine compound 47. Popp and coworkers 
A
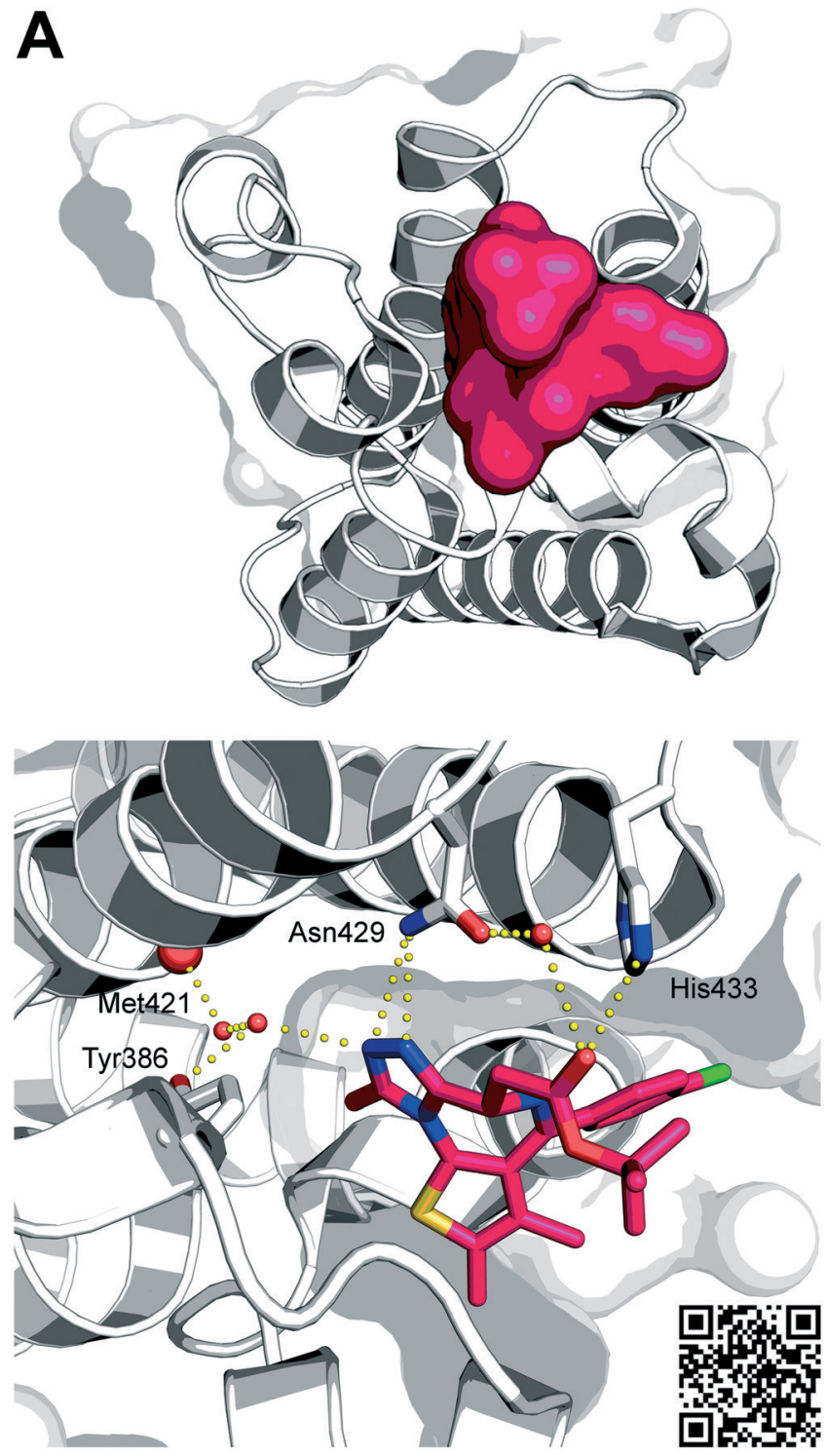

C

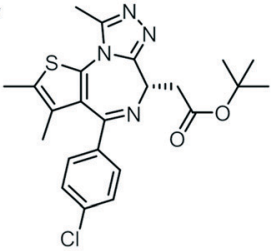

JQ1
43<smiles>Cc1nnn2c1-c1ccc(-c3ccc(N)nc3)cc1C(c1ccc(Cl)cc1)=NC2</smiles>

44

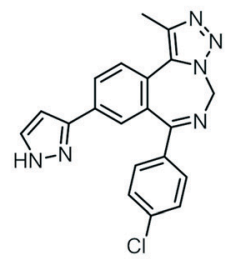

45
B

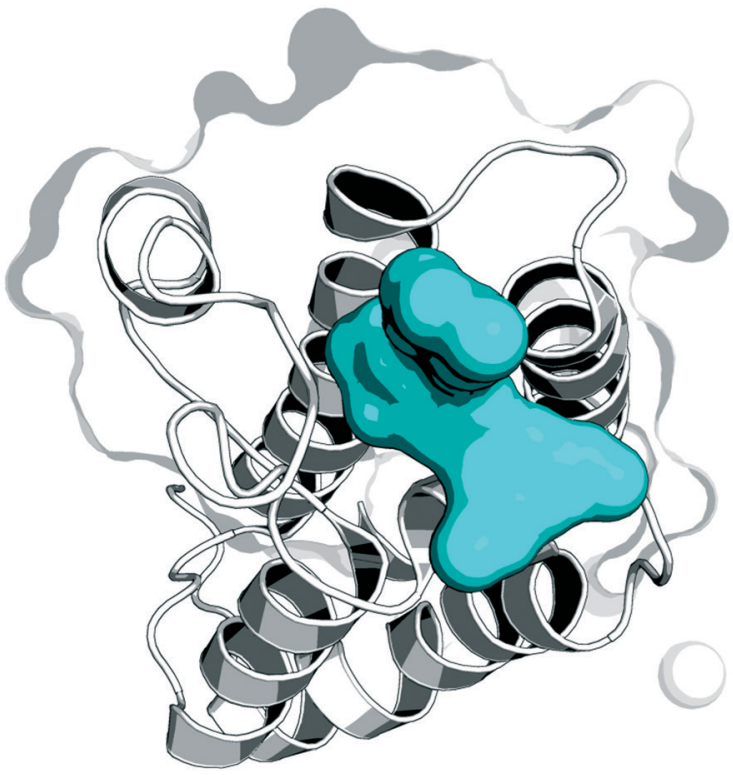

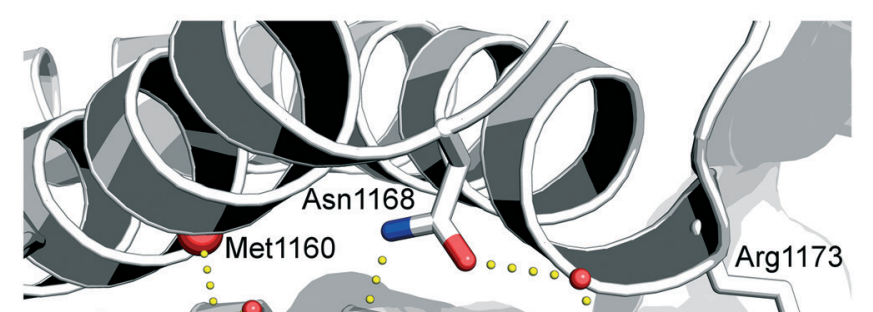

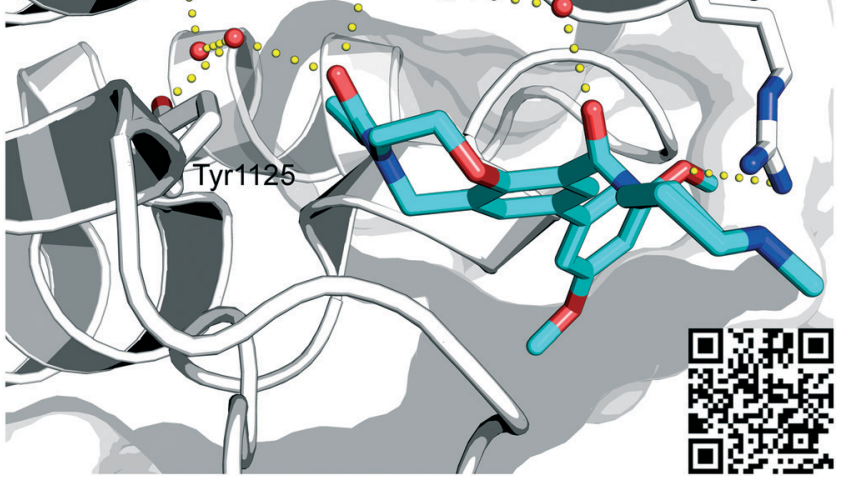<smiles>CCC(=O)N1CCOc2c(cc(-c3cc(OC)cc(OC)c3)cc2C(=O)NC2CCCN(C)C2)C1</smiles>

47

Fig. 12 Crystal structures of inhibitors JQ1 (A, 43, pink, PDB 3oni) and 47 (B, cyan, PDB 5j0d) in complex with Brd4 and CREBBP, respectively. The inhibitors occupy an analogous binding pocket thereby preventing binding of Brd4/CREBBP to acetylated lysines (non-interacting side chains are not shown for clarity purposes). C) Chemical structures of modulators of Brd4 (43-45) and CREBBP/p300 bromodomain (46-47). The QR codes can be visualized by the app Augment.

developed a series of compounds to establish a structure-activity relationship for this type of inhibitors. This compound exhibited excellent selectivity for CREBBP $\left(K_{\mathrm{d}}=134 \mathrm{nM}\right)$ over $\operatorname{Brd} 4\left(K_{\mathrm{d}}=5 \mu \mathrm{M}\right)$ and could be useful for the modulation of
CREB. The crystal structure of CREBBP (Fig. 12) underlined the proposed binding mode, and further cellular studies revealed the inhibitors potency, rendering it suitable for further preclinical studies. ${ }^{218,219}$ 


\section{Concluding remarks}

The interest in the field of TFs has rapidly grown within the last years. This is reflected by the vast number of publications released each week dealing with different aspects of TFs. Addressing these proteins with small molecules remains a challenging task majorly owing to the lack of known binding pockets within TFs and the large multiprotein complexes they participate in. Unlike protein target classes such as kinases or phosphatases, TFs lack similar structural features and often have no distinct folding in solution. This feature offers the opportunity for the development of selective inhibitors or activators, while making the discovery and optimization of such compounds a difficult process. This huge structural diversity leads to a cornucopia of different small molecules and peptidomimetics. Some molecules have already reached clinical application while others are currently undergoing clinical studies. The combination of increasing structural knowledge and novel biochemical, biophysical, and cellular screening methods will fuel the identification and development of potent, selective TF modulators that can serve as chemical probes or starting points for therapeutic agents. Furthermore, indirect approaches targeting TF cofactors and/or chromatin remodeling proteins represent valid schemes for the generation of broadly applicable drugs against numerous disease states with the goal of improved disease outcome.

\section{Conflicts of interest}

The authors declare no competing interest.

\section{Acknowledgements}

This work was co-funded by the German Federal Ministry for Education and Research (NGFNPlus and e:Med) (Grant No. BMBF 01GS08104, 01ZX1303C) and by the Deutsche Forschungsgemeinschaft (DFG). DR thanks the German federal state North Rhine Westphalia (NRW) and the European Union (European Regional Development Fund: Investing In Your Future) (EFRE-800400).

\section{References}

1 J. E. Darnell, Jr., Nat. Rev. Cancer, 2002, 2, 740-749.

2 C. Yan and P. J. Higgins, Biochim. Biophys. Acta, 2013, 1835, 76-85.

3 J. P. Overington, B. Al-Lazikani and A. L. Hopkins, Nat. Rev. Drug Discovery, 2006, 5, 993-996.

4 G. L. Plosker, Drugs, 2015, 75, 297-308.

5 C. M. Kuo, T. H. Tung, S. H. Wang and C. C. Chi, J. Eur. Acad. Dermatol. Venereol., 2018, 32(3), 355-362.

6 R. Camicia, H. C. Winkler and P. O. Hassa, Mol. Cancer, 2015, 14, 207.

7 A. S. Bhagwat and C. R. Vakoc, Trends Cancer, 2015, 1, 53-65.

8 T. J. Gonda and R. G. Ramsay, Nat. Rev. Cancer, 2015, 15, 686-694.
9 P. Wolle, M. P. Müller and D. Rauh, ACS Chem. Biol., 2018, 13, 496-499.

10 A. R. Wasylishen and L. Z. Penn, Genes Cancer, 2010, 1, 532-541.

11 R. Huang, N. K. Cheung, J. Vider, I. Y. Cheung, W. L. Gerald, S. K. Tickoo, E. C. Holland and R. G. Blasberg, FASEB J., 2011, 25, 4138-4149.

$12 \mathrm{~J}$. Vervoorts, J. Luscher-Firzlaff and B. Luscher, J. Biol. Chem., 2006, 281, 34725-34729.

13 E. M. Blackwood and R. N. Eisenman, Science, 1991, 251, 1211-1217.

14 T. K. Blackwell, L. Kretzner, E. M. Blackwood, R. N. Eisenman and H. Weintraub, Science, 1990, 250, 1149-1151.

15 E. M. Blackwood, B. Luscher and R. N. Eisenman, Genes Dev., 1992, 6, 71-80.

16 S. B. McMahon, H. A. Van Buskirk, K. A. Dugan, T. D. Copeland and M. D. Cole, Cell, 1998, 94, 363-374.

17 S. Kanazawa, L. Soucek, G. Evan, T. Okamoto and B. M. Peterlin, Oncogene, 2003, 22, 5707-5711.

18 J. Seoane, C. Pouponnot, P. Staller, M. Schader, M. Eilers and J. Massague, Nat. Cell Biol., 2001, 3, 400-408.

19 A. L. Gartel and K. Shchors, Exp. Cell Res., 2003, 283, $17-21$.

20 T. A. Brooks and L. H. Hurley, Genes Cancer, 2010, 1, 641-649.

21 A. Risitano and K. R. Fox, Biochemistry, 2003, 42, 6507-6513.

22 B. J. Chen, Y. L. Wu, Y. Tanaka and W. Zhang, Int. J. Biol. Sci., 2014, 10, 1084-1096.

23 J. Chauhan, H. Wang, J. L. Yap, P. E. Sabato, A. Hu, E. V. Prochownik and S. Fletcher, ChemMedChem, 2014, 9, 2274-2285.

24 J. Wanner, D. Romashko, D. S. Werner, E. W. May, Y. Peng, R. Schulz, K. W. Foreman, S. Russo, L. D. Arnold, M. Pingle, D. E. Bergstrom, F. Barany and S. Thomson, PLoS One, 2015, 10, e0121793.

25 X. Yin, C. Giap, J. S. Lazo and E. V. Prochownik, Oncogene, 2003, 22, 6151-6159.

26 J. Baell and M. A. Walters, Nature, 2014, 513, 481-483.

27 J. Parant, A. Chavez-Reyes, N. A. Little, W. Yan, V. Reinke, A. G. Jochemsen and G. Lozano, Nat. Genet., 2001, 29, 92-95.

28 C. M. Eischen, J. Mol. Cell Biol., 2017, 9, 69-73.

29 J. Massague, Cell, 2008, 134, 215-230.

30 K. Martin, D. Trouche, C. Hagemeier, T. S. Sorensen, N. B. La Thangue and T. Kouzarides, Nature, 1995, 375, 691-694.

31 X. Sui, S. Shin, R. Zhang, P. F. Firozi, L. Yang, J. L. Abbruzzese and S. A. Reddy, Oncogene, 2009, 28, 709-720.

32 E. E. Balint and K. H. Vousden, Br. J. Cancer, 2001, 85, 1813-1823.

33 S. J. Baker, S. Markowitz, E. R. Fearon, J. K. Willson and B. Vogelstein, Science, 1990, 249, 912-915.

34 N. J. Maclaine and T. R. Hupp, Aging, 2009, 1, 490-502.

35 K. H. Khoo, C. S. Verma and D. P. Lane, Nat. Rev. Drug Discovery, 2014, 13, 217-236. 
36 Q. Ding, Z. Zhang, J. J. Liu, N. Jiang, J. Zhang, T. M. Ross, X. J. Chu, D. Bartkovitz, F. Podlaski, C. Janson, C. Tovar, Z. M. Filipovic, B. Higgins, K. Glenn, K. Packman, L. T. Vassilev and B. Graves, J. Med. Chem., 2013, 56, 5979-5983.

37 A. R. Schneekloth, M. Pucheault, H. S. Tae and C. M. Crews, Bioorg. Med. Chem. Lett., 2008, 18, 5904-5908.

38 Y. Ma, B. R. Lahue, C. R. Gibeau, G. W. Shipps, Jr., S. L. Bogen, Y. Wang, Z. Guo and T. J. Guzi, ACS Med. Chem. Lett., 2014, 5, 572-575.

39 F. Meric-Bernstam, M. N. Saleh, J. R. Infante, S. Goel, G. S. Falchook, G. Shapiro, K. Y. Chung, R. M. Conry, D. S. Hong, J. S. Z. Wang, U. Steidl, L. D. Walensky, V. Guerlavais, M. Payton, D. A. Annis, M. Aivado and M. R. Patel, J. Clin. Oncol., 2017, 35, 2505.

40 M. Payton, D. Pinchasik, A. Mehta, S. Goel, J. M. Zain, L. Sokol, E. Jacobsen, M. R. Patel, S. M. Horwitz, F. MericBernstam, A. Shustov, D. Weinstock, M. Aivado and D. A. Annis, Ann. Oncol., 2017, 28, DOI: 10.1093/annonc/ mdx373.045.

41 J. E. Darnell, I. M. Kerr and G. R. Stark, Science, 1994, 264, 1415-1421.

42 T. J. Mitchell and S. John, Immunology, 2005, 114, 301-312.

43 S. Fletcher, J. Turkson and P. T. Gunning, ChemMedChem, 2008, 3, 1159-1168.

44 J. F. Bromberg, M. H. Wrzeszczynska, G. Devgan, Y. X. Zhao, R. G. Pestell, C. Albanese and J. E. Darnell, Cell, 1999, 98, 295-303.

45 P. K. Epling-Burnette, B. Zhong, F. Q. Bai, K. Jiang, R. D. Bailey, R. Garcia, R. Jove, J. Y. Djeu, T. P. Loughran and S. Wei, J. Immunol., 2001, 166, 7486-7495.

46 T. Bowman, M. A. Broome, D. Sinibaldi, W. Wharton, W. J. Pledger, J. M. Sedivy, R. Irby, T. Yeatman, S. A. Courtneidge and R. Jove, Proc. Natl. Acad. Sci. U. S. A., 2001, 98, 7319-7324.

47 R. Catlett-Falcone, T. H. Landowski, M. M. Oshiro, J. Turkson, A. Levitzki, R. Savino, G. Ciliberto, L. Moscinski, J. L. Fernandez-Luna, G. Nunez, W. S. Dalton and R. Jove, Immunity, 1999, 10, 105-115.

48 C. P. Lim and X. M. Cao, Mol. BioSyst., 2006, 2, 536-550.

49 G. Miklossy, T. S. Hilliard and J. Turkson, Nat. Rev. Drug Discovery, 2013, 12, 611-629.

50 N. Elumalai, K. Natarajan and T. Berg, Bioorg. Med. Chem., 2017, 25, 3871-3882.

51 N. Elumalai, A. Berg, S. Rubner, L. Blechschmidt, C. Song, K. Natarajan, J. Matysik and T. Berg, Sci. Rep., 2017, 7, 819.

52 M. G. LaPorte, Z. Wang, R. Colombo, A. Garzan, V. A. Peshkov, M. Liang, P. A. Johnston, M. E. Schurdak, M. Sen, D. P. Camarco, Y. Hua, N. I. Pollock, J. S. Lazo, J. R. Grandis, P. Wipf and D. M. Huryn, Bioorg. Med. Chem. Lett., 2016, 26, 3581-3585.

53 B. F. Kiesel, R. A. Parise, J. Guo, D. M. Huryn, P. A. Johnston, R. Colombo, M. Sen, J. R. Grandis, J. H. Beumer and J. L. Eiseman, Cancer Chemother. Pharmacol., 2016, 78, 1225-1235.

54 M. A. Blaskovich, J. Sun, A. Cantor, J. Turkson, R. Jove and S. M. Sebti, Cancer Res., 2003, 63, 1270-1279.

55 S. M. Garg, M. R. Vakili, O. Molavi and A. Lavasanifar, Mol. Pharmaceutics, 2017, 14(8), 2570-2584.
56 J. Schust, B. Sperl, A. Hollis, T. U. Mayer and T. Berg, Chem. Biol., 2006, 13, 1235-1242.

57 V. Leidgens, J. Proske, L. Rauer, S. Moeckel, K. Renner, U. Bogdahn, M. J. Riemenschneider, M. Proescholdt, A. Vollmann-Zwerenz, P. Hau and C. Seliger, Oncotarget, 2017, 8, 8250-8263.

58 M. Pajares, A. Cuadrado and A. I. Rojo, Redox Biol., 2017, 11, 543-553.

59 X. J. Wang, Z. Sun, N. F. Villeneuve, S. Zhang, F. Zhao, Y. Li, W. Chen, X. Yi, W. Zheng, G. T. Wondrak, P. K. Wong and D. D. Zhang, Carcinogenesis, 2008, 29, 1235-1243.

60 J. D. Hayes and M. McMahon, Trends Biochem. Sci., 2009, 34, 176-188.

61 K. I. Tong, A. Kobayashi, F. Katsuoka and M. Yamamoto, Biol. Chem., 2006, 387, 1311-1320.

62 K. Taguchi, H. Motohashi and M. Yamamoto, Genes Cells, 2011, 16, 123-140.

63 Y. S. Chang, B. Graves, V. Guerlavais, C. Tovar, K. Packman, K. H. To, K. A. Olson, K. Kesavan, P. Gangurde, A. Mukherjee, T. Baker, K. Darlak, C. Elkin, Z. Filipovic, F. Z. Qureshi, H. L. Cai, P. Berry, E. Feyfant, X. G. E. Shi, J. Horstick, D. A. Annis, A. M. Manning, N. Fotouhi, H. Nash, L. T. Vassilev and T. K. Sawyer, Proc. Natl. Acad. Sci. U. S. A., 2013, 110, E3445-E3454.

64 K. Itoh, T. Chiba, S. Takahashi, T. Ishii, K. Igarashi, Y. Katoh, T. Oyake, N. Hayashi, K. Satoh, I. Hatayama, M. Yamamoto and Y. Nabeshima, Biochem. Biophys. Res. Commun., 1997, 236, 313-322.

65 G. Shen and A. N. Kong, Biopharm. Drug Dispos., 2009, 30, 345-355.

66 M. C. Lu, J. A. Ji, Z. Y. Jiang and Q. D. You, Med. Res. Rev., 2016, 36, 924-963.

67 D. Yasuda, M. Nakajima, A. Yuasa, R. Obata, K. Takahashi, T. Ohe, Y. Ichimura, M. Komatsu, M. Yamamoto, R. Imamura, H. Kojima, T. Okabe, T. Nagano and T. Mashino, Bioorg. Med. Chem. Lett., 2016, 26, 5956-5959.

68 A. Singh, S. Venkannagari, K. H. Oh, Y. Q. Zhang, J. M. Rohde, L. Liu, S. Nimmagadda, K. Sudini, K. R. Brimacombe, S. Gajghate, J. Ma, A. Wang, X. Xu, S. A. Shahane, M. Xia, J. Woo, G. A. Mensah, Z. Wang, M. Ferrer, E. Gabrielson, Z. Li, F. Rastinejad, M. Shen, M. B. Boxer and S. Biswal, ACS Chem. Biol., 2016, 11, 3214-3225.

69 T. G. Davies, W. E. Wixted, J. E. Coyle, C. Griffiths-Jones, K. Hearn, R. McMenamin, D. Norton, S. J. Rich, C. Richardson, G. Saxty, H. M. Willems, A. J. Woolford, J. E. Cottom, J. P. Kou, J. G. Yonchuk, H. G. Feldser, Y. Sanchez, J. P. Foley, B. J. Bolognese, G. Logan, P. L. Podolin, H. Yan, J. F. Callahan, T. D. Heightman and J. K. Kerns, J. Med. Chem., 2016, 59, 3991-4006.

70 A. J. Shaywitz and M. E. Greenberg, Annu. Rev. Biochem., 1999, 68, 821-861.

71 B. E. Lonze and D. D. Ginty, Neuron, 2002, 35, 605-623.

72 M. A. Schumacher, R. H. Goodman and R. G. Brennan, J. Biol. Chem., 2000, 275, 35242-35247.

73 C. Vinson, M. Myakishev, A. Acharya, A. A. Mir, J. R. Moll and M. Bonovich, Mol. Cell. Biol., 2002, 22, 6321-6335. 
74 X. Xiao, B. X. Li, B. Mitton, A. Ikeda and K. M. Sakamoto, Curr. Cancer Drug Targets, 2010, 10, 384-391.

75 V. V. Ogryzko, R. L. Schiltz, V. Russanova, B. H. Howard and Y. Nakatani, Cell, 1996, 87, 953-959.

76 J. M. Kornhauser, C. W. Cowan, A. J. Shaywitz, R. E. Dolmetsch, E. C. Griffith, L. S. Hu, C. Haddad, Z. Xia and M. E. Greenberg, Neuron, 2002, 34, 221-233.

77 E. R. Kandel, Mol. Brain, 2012, 5, 14.

78 D. Wu, H. E. Zhau, W. C. Huang, S. Iqbal, F. K. Habib, O. Sartor, L. Cvitanovic, F. F. Marshall, Z. Xu and L. W. Chung, Oncogene, 2007, 26, 5070-5077.

79 D. B. Shankar, J. C. Cheng, K. Kinjo, N. Federman, T. B. Moore, A. Gill, N. P. Rao, E. M. Landaw and K. M. Sakamoto, Cancer Cell, 2005, 7, 351-362.

80 K. M. Sakamoto and D. A. Frank, Clin. Cancer Res., 2009, 15, 2583-2587.

81 W. A. Carlezon Jr., R. S. Duman and E. J. Nestler, Trends Neurosci., 2005, 28, 436-445.

82 G. M. Nitulescu, D. Margina, P. Juzenas, Q. Peng, O. T. Olaru, E. Saloustros, C. Fenga, D. Spandidos, M. Libra and A. M. Tsatsakis, Int. J. Oncol., 2016, 48, 869-885.

83 J. L. Best, C. A. Amezcua, B. Mayr, L. Flechner, C. M. Murawsky, B. Emerson, T. Zor, K. H. Gardner and M. Montminy, Proc. Natl. Acad. Sci. U. S. A., 2004, 101, 17622-17627.

84 B. X. Li and X. Xiao, ChemBioChem, 2009, 10, 2721-2724.

85 M. Jiang, B. X. Li, F. Xie, F. Delaney and X. Xiao, J. Med. Chem., 2012, 55, 4020-4024.

86 F. Xie, B. X. Li, A. Kassenbrock, C. Xue, X. Wang, D. Z. Qian, R. C. Sears and X. Xiao, J. Med. Chem., 2015, 58, 5075-5087.

87 B. X. Li, R. Gardner, C. Xue, D. Z. Qian, F. Xie, G. Thomas, S. C. Kazmierczak, B. A. Habecker and X. Xiao, Sci. Rep., 2016, 6, 34513.

88 N. Mambetsariev, W. W. Lin, L. L. Stunz, B. M. Hanson, J. M. Hildebrand and G. A. Bishop, Proc. Natl. Acad. Sci. U. S. A., 2016, 113, 1032-1037.

89 B. Mitton, H. D. Chae, K. Hsu, R. Dutta, G. AldanaMasangkay, R. Ferrari, K. Davis, B. C. Tiu, A. Kaul, N. Lacayo, G. Dahl, F. Xie, B. X. Li, M. R. Breese, E. M. Landaw, G. Nolan, M. Pellegrini, S. Romanov, X. Xiao and K. M. Sakamoto, Leukemia, 2016, 30, 2302-2311.

90 A. Steven, S. Leisz, C. Wickenhauser, K. Schulz, D. Mougiakakos, R. Kiessling, C. Denkert and B. Seliger, Oncotarget, 2017, 8, 97439-97463.

91 J. M. Olefsky, J. Biol. Chem., 2001, 276, 36863-36864.

92 N. Novac and T. Heinzel, Curr. Drug Targets: Inflammation Allergy, 2004, 3, 335-346.

93 B. J. Deroo and K. S. Korach, J. Clin. Invest., 2006, 116, 561-570.

94 N. Heldring, A. Pike, S. Andersson, J. Matthews, G. Cheng, J. Hartman, M. Tujague, A. Strom, E. Treuter, M. Warner and J. A. Gustafsson, Physiol. Rev., 2007, 87, 905-931.

95 S. C. Mayer-Wrangowski and D. Rauh, Angew. Chem., Int. Ed., 2015, 54, 4379-4382.

96 D. J. Kojetin, E. Matta-Camacho, T. S. Hughes, S. Srinivasan, J. C. Nwachukwu, V. Cavett, J. Nowak, M. J.
Chalmers, D. P. Marciano, T. M. Kamenecka, A. I. Shulman, M. Rance, P. R. Griffin, J. B. Bruning and K. W. Nettles, Nat. Commun., 2015, 6, 8013.

97 S. W. Fanning, C. G. Mayne, V. Dharmarajan, K. E. Carlson, T. A. Martin, S. J. Novick, W. Toy, B. Green, S. Panchamukhi, B. S. Katzenellenbogen, E. Tajkhorshid, P. R. Griffin, Y. Shen, S. Chandarlapaty, J. A. Katzenellenbogen and G. L. Greene, Elife, 2016, 5, e12792.

98 D. R. Robinson, Y. M. Wu, P. Vats, F. Su, R. J. Lonigro, X. Cao, S. Kalyana-Sundaram, R. Wang, Y. Ning, L. Hodges, A. Gursky, J. Siddiqui, S. A. Tomlins, S. Roychowdhury, K. J. Pienta, S. Y. Kim, J. S. Roberts, J. M. Rae, C. H. Van Poznak, D. F. Hayes, R. Chugh, L. P. Kunju, M. Talpaz, A. F. Schott and A. M. Chinnaiyan, Nat. Genet., 2013, 45, 1446-1451.

99 W. Toy, Y. Shen, H. Won, B. Green, R. A. Sakr, M. Will, Z. Li, K. Gala, S. Fanning, T. A. King, C. Hudis, D. Chen, T. Taran, G. Hortobagyi, G. Greene, M. Berger, J. Baselga and S. Chandarlapaty, Nat. Genet., 2013, 45, 1439-1445.

100 J. B. Bruning, A. A. Parent, G. Gil, M. Zhao, J. Nowak, M. C. Pace, C. L. Smith, P. V. Afonine, P. D. Adams, J. A. Katzenellenbogen and K. W. Nettles, Nat. Chem. Biol., 2010, 6, 837-843.

101 S. Shibutani, A. Ravindernath, I. Terashima, N. Suzuki, Y. R. Laxmi, Y. Kanno, M. Suzuki, T. I. Apak, J. J. Sheng and M. W. Duffel, Cancer Res., 2001, 61, 3925-3931.

102 S. Martinkovich, D. Shah, S. L. Planey and J. A. Arnott, Clin. Interventions Aging, 2014, 9, 1437-1452.

103 F. Garner, M. Shomali, D. Paquin, C. R. Lyttle and G. Hattersley, Anti-Cancer Drugs, 2015, 26, 948-956.

104 A. Lai, M. Kahraman, S. Govek, J. Nagasawa, C. Bonnefous, J. Julien, K. Douglas, J. Sensintaffar, N. Lu, K. J. Lee, A. Aparicio, J. Kaufman, J. Qian, G. Shao, R. Prudente, M. J. Moon, J. D. Joseph, B. Darimont, D. Brigham, K. Grillot, R. Heyman, P. J. Rix, J. H. Hager and N. D. Smith, J. Med. Chem., 2015, 58, 4888-4904.

105 C. De Savi, R. H. Bradbury, A. A. Rabow, R. A. Norman, C. de Almeida, D. M. Andrews, P. Ballard, D. Buttar, R. J. Callis, G. S. Currie, J. O. Curwen, C. D. Davies, C. S. Donald, L. J. Feron, H. Gingell, S. C. Glossop, B. R. Hayter, S. Hussain, G. Karoutchi, S. G. Lamont, P. MacFaul, T. A. Moss, S. E. Pearson, M. Tonge, G. E. Walker, H. M. Weir and Z. Wilson, J. Med. Chem., 2015, 58, 8128-8140.

106 H. M. Weir, R. H. Bradbury, M. Lawson, A. A. Rabow, D. Buttar, R. J. Callis, J. O. Curwen, C. de Almeida, P. Ballard, M. Hulse, C. S. Donald, L. J. Feron, G. Karoutchi, P. MacFaul, T. Moss, R. A. Norman, S. E. Pearson, M. Tonge, G. Davies, G. E. Walker, Z. Wilson, R. Rowlinson, S. Powell, C. Sadler, G. Richmond, B. Ladd, E. Pazolli, A. M. Mazzola, C. D'Cruz and C. De Savi, Cancer Res., 2016, 76, 3307-3318.

107 D. P. McDonnell, S. E. Wardell and J. D. Norris, J. Med. Chem., 2015, 58, 4883-4887.

108 S. E. Wardell, M. J. Ellis, H. M. Alley, K. Eisele, T. VanArsdale, S. G. Dann, K. T. Arndt, T. Primeau, E. Griffin, J. Shao, R. Crowder, J. P. Lai, J. D. Norris, D. P. McDonnell and S. Li, Clin. Cancer Res., 2015, 21, 5121-5130. 
109 N. C. Turner, J. Ro, F. Andre, S. Loi, S. Verma, H. Iwata, N. Harbeck, S. Loibl, C. Huang Bartlett, K. Zhang, C. Giorgetti, S. Randolph, M. Koehler, M. Cristofanilli and P. S. Group, N. Engl. J. Med., 2015, 373, 209-219.

110 P. Huang, V. Chandra and F. Rastinejad, Annu. Rev. Physiol., 2010, 72, 247-272.

111 D. J. Mangelsdorf, C. Thummel, M. Beato, P. Herrlich, G. Schutz, K. Umesono, B. Blumberg, P. Kastner, M. Mark, P. Chambon and R. M. Evans, Cell, 1995, 83, 835-839.

112 G. Verrijdt, A. Haelens and F. Claessens, Mol. Genet. Metab., 2003, 78, 175-185.

113 T. Matsumoto, M. Sakari, M. Okada, A. Yokoyama, S. Takahashi, A. Kouzmenko and S. Kato, Annu. Rev. Physiol., 2013, 75, 201-224.

114 A. D. Mooradian, J. E. Morley and S. G. Korenman, Endocr. Rev., 1987, 8, 1-28.

115 X. Zhang and Z. Sui, Expert Opin. Drug Discovery, 2013, 8, 191-218.

116 I. A. Hughes, J. D. Davies, T. I. Bunch, V. Pasterski, K. Mastroyannopoulou and J. MacDougall, Lancet, 2012, 380, 1419-1428.

117 C. A. Heinlein and C. Chang, Endocr. Rev., 2004, 25, 276-308.

118 G. C. Shukla, A. R. Plaga, E. Shankar and S. Gupta, Andrology, 2016, 4, 366-381.

119 P. R. Ebeling, Curr. Opin. Endocrinol., Diabetes Obes., 2010, 17, 284-292.

120 G. J. Kolvenbag, G. R. Blackledge and K. Gotting-Smith, Prostate, 1998, 34, 61-72.

121 S. Patel, Ann. Rheum. Dis., 1996, 55, 700-714.

122 S. Basaria, J. T. Wahlstrom and A. S. Dobs, J. Clin. Endocrinol. Metab., 2001, 86, 5108-5117.

123 P. Reid, P. Kantoff and W. Oh, Invest. New Drugs, 1999, 17, 271-284.

124 W. Gao and J. T. Dalton, Drug Discovery Today, 2007, 12, 241-248.

125 C. Helsen, T. Van den Broeck, A. Voet, S. Prekovic, H. Van Poppel, S. Joniau and F. Claessens, Endocr.-Relat. Cancer, 2014, 21, T105-T118.

126 G. N. Brooke and C. L. Bevan, Curr. Genomics, 2009, 10, 18-25.

127 K. Eisermann, D. Wang, Y. Jing, L. E. Pascal and Z. Wang, Transl. Androl. Urol., 2013, 2, 137-147.

128 M. Nadal, S. Prekovic, N. Gallastegui, C. Helsen, M. Abella, K. Zielinska, M. Gay, M. Vilaseca, M. Taules, A. B. Houtsmuller, M. E. van Royen, F. Claessens, P. FuentesPrior and E. Estebanez-Perpina, Nat. Commun., 2017, 8, 14388.

129 A. M. Moilanen, R. Riikonen, R. Oksala, L. Ravanti, E. Aho, G. Wohlfahrt, P. S. Nykanen, O. P. Tormakangas, J. J. Palvimo and P. J. Kallio, Sci. Rep., 2015, 5, 12007.

130 J. P. Bergerat and J. Ceraline, Hum. Mutat., 2009, 30, 145-157.

131 I. J. McEwan and A. O. Brinkmann, in Endotext, ed. L. J. De Groot, G. Chrousos, K. Dungan, K. R. Feingold, A. Grossman, J. M. Hershman, C. Koch, M. Korbonits, R. McLachlan, M. New, J. Purnell, R. Rebar, F. Singer and A. Vinik, South Dartmouth (MA), 2000.
132 X. Y. Zhao, P. J. Malloy, A. V. Krishnan, S. Swami, N. M. Navone, D. M. Peehl and D. Feldman, Nat. Med., 2000, 6, 703-706.

133 C. E. Bohl, W. Gao, D. D. Miller, C. E. Bell and J. T. Dalton, Proc. Natl. Acad. Sci. U. S. A., 2005, 102, 6201-6206.

134 M. E. Taplin, B. Rajeshkumar, S. Halabi, C. P. Werner, B. A. Woda, J. Picus, W. Stadler, D. F. Hayes, P. W. Kantoff, N. J. Vogelzang, E. J. Small and Cancer and B. S. Leukemia Group, J. Clin. Oncol., 2003, 21, 2673-2678.

135 M. D. Balbas, M. J. Evans, D. J. Hosfield, J. Wongvipat, V. K. Arora, P. A. Watson, Y. Chen, G. L. Greene, Y. Shen and C. L. Sawyers, Elife, 2013, 2, e00499.

136 J. D. Joseph, N. Lu, J. Qian, J. Sensintaffar, G. Shao, D. Brigham, M. Moon, E. C. Maneval, I. Chen, B. Darimont and J. H. Hager, Cancer Discovery, 2013, 3, 1020-1029.

137 K. Fizazi, C. Massard, P. Bono, R. Jones, V. Kataja, N. James, J. A. Garcia, A. Protheroe, T. L. Tammela, T. Elliott, L. Mattila, J. Aspegren, A. Vuorela, P. Langmuir, M. Mustonen and A. S. Group, Lancet Oncol., 2014, 15, 975-985.

138 R. H. Bradbury, N. J. Hales, A. A. Rabow, G. E. Walker, D. G. Acton, D. M. Andrews, P. Ballard, N. A. Brooks, N. Colclough, A. Girdwood, U. J. Hancox, O. Jones, D. Jude, S. A. Loddick and A. A. Mortlock, Bioorg. Med. Chem. Lett., 2011, 21, 5442-5445.

139 R. H. Bradbury, D. G. Acton, N. L. Broadbent, A. N. Brooks, G. R. Carr, G. Hatter, B. R. Hayter, K. J. Hill, N. J. Howe, R. D. Jones, D. Jude, S. G. Lamont, S. A. Loddick, H. L. McFarland, Z. Parveen, A. A. Rabow, G. Sharma-Singh, N. C. Stratton, A. G. Thomason, D. Trueman, G. E. Walker, S. L. Wells, J. Wilson and J. M. Wood, Bioorg. Med. Chem. Lett., 2013, 23, 1945-1948.

140 A. Omlin, R. J. Jones, R. van der Noll, T. Satoh, M. Niwakawa, S. A. Smith, J. Graham, M. Ong, R. D. Finkelman, J. H. Schellens, A. Zivi, M. Crespo, R. Riisnaes, D. Nava-Rodrigues, M. D. Malone, C. Dive, R. Sloane, D. Moore, J. J. Alumkal, A. Dymond, P. A. Dickinson, M. Ranson, G. Clack, J. de Bono and T. Elliott, Invest. New Drugs, 2015, 33, 679-690.

141 R. Williams, Expert Opin. Invest. Drugs, 2013, 22, 1627-1644.

142 J. L. Gustafson, T. K. Neklesa, C. S. Cox, A. G. Roth, D. L. Buckley, H. S. Tae, T. B. Sundberg, D. B. Stagg, J. Hines, D. P. McDonnell, J. D. Norris and C. M. Crews, Angew. Chem., Int. Ed., 2015, 54, 9659-9662.

143 T. K. Neklesa, M. Jin, A. P. Crew, A. M. K. Rossi, R. R. Willard, H. Dong, K. Siu, J. Wang, D. A. Gordon, X. Chen, C. Ferraro, C. M. Crews, K. Coleman and J. D. Winkler, J. Clin. Oncol., 2016, 34, 267.

144 R. J. Andersen, N. R. Mawji, J. Wang, G. Wang, S. Haile, J. K. Myung, K. Watt, T. Tam, Y. C. Yang, C. A. Banuelos, D. E. Williams, I. J. McEwan, Y. Wang and M. D. Sadar, Cancer Cell, 2010, 17, 535-546.

145 E. S. Antonarakis, C. Chandhasin, E. Osbourne, J. Luo, M. D. Sadar and F. Perabo, Oncologist, 2016, 21, 1427-1435.

146 E. S. Antonarakis, C. Lu, H. Wang, B. Luber, M. Nakazawa, J. C. Roeser, Y. Chen, T. A. Mohammad, Y. Chen, H. L. 
Fedor, T. L. Lotan, Q. Zheng, A. M. De Marzo, J. T. Isaacs, W. B. Isaacs, R. Nadal, C. J. Paller, S. R. Denmeade, M. A. Carducci, M. A. Eisenberger and J. Luo, N. Engl. J. Med., 2014, 371, 1028-1038.

147 G. L. Semenza, Trends Mol. Med., 2002, 8, S62-S67.

148 G. L. Semenza, Sci. STKE, 2007, 2007, cm8.

149 V. H. Haase, Blood Rev., 2013, 27, 41-53.

150 G. L. Semenza, Cell, 2012, 148, 399-408.

151 T. Kietzmann, D. Mennerich and E. Y. Dimova, Front Cell Dev. Biol., 2016, 4, 11.

152 R. H. Wenger, D. P. Stiehl and G. Camenisch, Sci. STKE, 2005, 2005, re12.

153 A. Zimna and M. Kurpisz, Biomed Res. Int., 2015, 2015, 549412.

154 C. Duan, Am. J. Physiol., Cell Physiol., 2016, 310, C260-C269.

155 N. Masson, C. Willam, P. H. Maxwell, C. W. Pugh and P. J. Ratcliffe, EMBO J., 2001, 20, 5197-5206.

156 D. Lando, D. J. Peet, D. A. Whelan, J. J. Gorman and M. L. Whitelaw, Science, 2002, 295, 858-861.

157 E. B. Rankin and A. J. Giaccia, Science, 2016, 352, 175-180.

158 B. J. Moeller, Y. Cao, C. Y. Li and M. W. Dewhirst, Cancer Cell, 2004, 5, 429-441.

159 S. E. Wilkins, M. I. Abboud, R. L. Hancock and C. J. Schofield, ChemMedChem, 2016, 11, 773-786.

160 D. Wu, N. Potluri, J. Lu, Y. Kim and F. Rastinejad, Nature, 2015, 524, 303-308.

161 T. H. Scheuermann, D. Stroud, C. E. Sleet, L. Bayeh, C. Shokri, H. Wang, C. G. Caldwell, J. Longgood, J. B. MacMillan, R. K. Bruick, K. H. Gardner and U. K. Tambar, J. Med. Chem., 2015, 58, 5930-5941.

162 H. Cho, X. Du, J. P. Rizzi, E. Liberzon, A. A. Chakraborty, W. Gao, I. Carvo, S. Signoretti, R. K. Bruick, J. A. Josey, E. M. Wallace and W. G. Kaelin, Nature, 2016, 539, 107-111.

163 T. H. Scheuermann, Q. Li, H. W. Ma, J. Key, L. Zhang, R. Chen, J. A. Garcia, J. Naidoo, J. Longgood, D. E. Frantz, U. K. Tambar, K. H. Gardner and R. K. Bruick, Nat. Chem. Biol., 2013, 9, 271-276.

164 M. C. Chan, J. P. Holt-Martyn, C. J. Schofield and P. J. Ratcliffe, Mol. Aspects Med., 2016, 47-48, 54-75.

165 I. Flamme, F. Oehme, P. Ellinghaus, M. Jeske, J. Keldenich and U. Thuss, PLoS One, 2014, 9, e111838.

166 A. Besarab, E. Chernyavskaya, I. Motylev, E. Shutov, L. M. Kumbar, K. Gurevich, D. T. Chan, R. Leong, L. Poole, M. Zhong, K. G. Saikali, M. Franco, S. Hemmerich, K. H. Yu and T. B. Neff, J. Am. Soc. Nephrol., 2016, 27, 1225-1233.

167 E. Olson, L. Demopoulos, T. F. Haws, E. Hu, Z. Fang, K. M. Mahar, P. Qin, J. Lepore, T. A. Bauer and W. R. Hiatt, Vasc. Med., 2014, 19, 473-482.

168 M. C. Chan, N. E. Ilott, J. Schodel, D. Sims, A. Tumber, K. Lippl, D. R. Mole, C. W. Pugh, P. J. Ratcliffe, C. P. Ponting and C. J. Schofield, J. Biol. Chem., 2016, 291, 20661-20673.

169 S. R. Mooring, H. Jin, N. S. Devi, A. A. Jabbar, S. Kaluz, Y. Liu, E. G. Van Meir and B. Wang, J. Med. Chem., 2011, 54, 8471-8489.
170 S. Yin, S. Kaluz, N. S. Devi, A. A. Jabbar, R. G. de Noronha, J. Mun, Z. Zhang, P. R. Boreddy, W. Wang, Z. Wang, T. Abbruscato, Z. Chen, J. J. Olson, R. Zhang, M. M. Goodman, K. C. Nicolaou and E. G. Van Meir, Clin. Cancer Res., 2012, 18, 6623-6633.

171 J. H. Ferguson, Z. De Los Santos, S. N. Devi, S. Kaluz, E. G. Van Meir, S. K. Zingales and B. Wang, J. Enzyme Inhib. Med. Chem., 2017, 32, 992-1001.

172 D. L. Buckley, I. Van Molle, P. C. Gareiss, H. S. Tae, J. Michel, D. J. Noblin, W. L. Jorgensen, A. Ciulli and C. M. Crews, J. Am. Chem. Soc., 2012, 134, 4465-4468.

173 C. Galdeano, M. S. Gadd, P. Soares, S. Scaffidi, I. Van Molle, I. Birced, S. Hewitt, D. M. Dias and A. Ciulli, J. Med. Chem., 2014, 57, 8657-8663.

174 J. Frost, C. Galdeano, P. Soares, M. S. Gadd, K. M. Grzes, L. Ellis, O. Epemolu, S. Shimamura, M. Bantscheff, P. Grandi, K. D. Read, D. A. Cantrell, S. Rocha and A. Ciulli, Nat. Commun., 2016, 7, 13312.

175 D. P. Bondeson, A. Mares, I. E. Smith, E. Ko, S. Campos, A. H. Miah, K. E. Mulholland, N. Routly, D. L. Buckley, J. L. Gustafson, N. Zinn, P. Grandi, S. Shimamura, G. Bergamini, M. Faelth-Savitski, M. Bantscheff, C. Cox, D. A. Gordon, R. R. Willard, J. J. Flanagan, L. N. Casillas, B. J. Votta, W. den Besten, K. Famm, L. Kruidenier, P. S. Carter, J. D. Harling, I. Churcher and C. M. Crews, Nat. Chem. Biol., 2015, 11, 611-617.

176 M. S. Hayden and S. Ghosh, Genes Dev., 2012, 26, 203-234.

177 S. Prasad, J. Ravindran and B. B. Aggarwal, Mol. Cell. Biochem., 2010, 336, 25-37.

178 L. M. Staudt, Cold Spring Harbor Perspect. Biol., 2010, 2, a000109.

179 T. D. Gilmore, Cell, 1990, 62, 841-843.

180 T. D. Gilmore, Oncogene, 2006, 25, 6680-6684.

181 M. Karin and Y. Ben-Neriah, Annu. Rev. Immunol., 2000, 18, 621-663.

182 D. Plaksin, P. A. Baeuerle and L. Eisenbach, J. Exp. Med., 1993, 177, 1651-1662.

183 O. V. Savinova, A. Hoffmann and G. Ghosh, Mol. Cell, 2009, 34, 591-602.

184 B. Hoesel and J. A. Schmid, Mol. Cancer, 2013, 12, 86.

185 N. D. Perkins, Nat. Rev. Mol. Cell Biol., 2007, 8, 49-62.

186 S. C. Sun, Cell Res., 2011, 21, 71-85.

187 U. Senftleben, Y. Cao, G. Xiao, F. R. Greten, G. Krahn, G. Bonizzi, Y. Chen, Y. Hu, A. Fong, S. C. Sun and M. Karin, Science, 2001, 293, 1495-1499.

188 A. Oeckinghaus and S. Ghosh, Cold Spring Harbor Perspect. Biol., 2009, 1, a000034.

189 K. P. Zeligs, M. K. Neuman and C. M. Annunziata, Clin. Cancer Res., 2016, 22, 4302-4308.

190 S. I. Grivennikov, F. R. Greten and M. Karin, Cell, 2010, 140, 883-899.

191 T. D. Gilmore and M. Herscovitch, Oncogene, 2006, 25, 6887-6899.

192 S. C. Gupta, C. Sundaram, S. Reuter and B. B. Aggarwal, Biochim. Biophys. Acta, 2010, 1799, 775-787.

193 M. Kanduri, G. Tobin, A. Aleskog, K. Nilsson and R. Rosenquist, Blood Cancer J., 2011, 1, e12. 
194 A. Gomez-Cabrero, W. Wrasidlo and R. A. Reisfeld, PLoS One, 2013, 8, e73607.

195 T. Hideshima, H. Ikeda, D. Chauhan, Y. Okawa, N. Raje, K. Podar, C. Mitsiades, N. C. Munshi, P. G. Richardson, R. D. Carrasco and K. C. Anderson, Blood, 2009, 114, 1046-1052.

196 A. Juvekar, S. Manna, S. Ramaswami, T. P. Chang, H. Y. Vu, C. C. Ghosh, M. Y. Celiker and I. Vancurova, Mol. Cancer Res., 2011, 9, 183-194.

197 G. M. Matthews, R. de Matos Simoes, E. Dhimolea, M. Sheffer, S. Gandolfi, O. Dashevsky, J. D. Sorrell and C. S. Mitsiades, Semin. Cancer Biol., 2016, 39, 68-76.

198 C. Fabre, N. Mimura, K. Bobb, S. Y. Kong, G. Gorgun, D. Cirstea, Y. Hu, J. Minami, H. Ohguchi, J. Zhang, J. Meshulam, R. D. Carrasco, Y. T. Tai, P. G. Richardson, T. Hideshima and K. C. Anderson, Clin. Cancer Res., 2012, 18, 4669-4681.

199 C. M. Blakely, E. Pazarentzos, V. Olivas, S. Asthana, J. J. Yan, I. Tan, G. Hrustanovic, E. Chan, L. Lin, D. S. Neel, W. Newton, K. L. Bobb, T. R. Fouts, J. Meshulam, M. A. Gubens, D. M. Jablons, J. R. Johnson, S. Bandyopadhyay, N. J. Krogan and T. G. Bivona, Cell Rep., 2015, 11, 98-110.

200 Y. N. Demchenko, L. A. Brents, Z. Li, L. P. Bergsagel, L. R. McGee and M. W. Kuehl, Oncotarget, 2014, 5, 4554-4566.

201 G. M. Castanedo, N. Blaquiere, M. Beresini, B. Bravo, H. Brightbill, J. Chen, H. F. Cui, C. Eigenbrot, C. Everett, J. Feng, R. Godemann, E. Gogol, S. Hymowitz, A. Johnson, N. Kayagaki, P. B. Kohli, K. Knuppel, J. Kraemer, S. Kruger, P. Loke, P. McEwan, C. Montalbetti, D. A. Roberts, M. Smith, S. Steinbacher, S. Sujatha-Bhaskar, R. Takahashi, X. Wang, L. C. Wu, Y. Zhang and S. T. Staben, J. Med. Chem., 2017, 60, 627-640.

202 Y. Shono, A. Z. Tuckett, H. C. Liou, E. Doubrovina, E. Derenzini, S. Ouk, J. J. Tsai, O. M. Smith, E. R. Levy, F. M. Kreines, C. G. Ziegler, M. I. Scallion, M. Doubrovin, G. Heller, A. Younes, R. J. O'Reilly, M. R. van den Brink and J. L. Zakrzewski, Cancer Res., 2016, 76, 377-389.

203 Y. Shono, A. Z. Tuckett, S. Ouk, H. C. Liou, G. Altan-Bonnet, J. J. Tsai, J. E. Oyler, O. M. Smith, M. L. West, N. V. Singer, E. Doubrovina, D. Pankov, C. V. Undhad, G. F. Murphy, C. Lezcano, C. Liu, R. J. O'Reilly, M. R. van den Brink and J. L. Zakrzewski, Cancer Discovery, 2014, 4, 578-591.

204 D. B. Doroshow, J. P. Eder and P. M. LoRusso, Ann. Oncol., 2017, 28, 1776-1787.

205 Y. Taniguchi, Int. J. Mol. Sci., 2016, 17, 1849.

206 W. A. Whyte, D. A. Orlando, D. Hnisz, B. J. Abraham, C. Y. Lin, M. H. Kagey, P. B. Rahl, T. I. Lee and R. A. Young, Cell, 2013, 153, 307-319.

207 S. Pott and J. D. Lieb, Nat. Genet., 2015, 47, 8-12.

208 B. Chapuy, M. R. McKeown, C. Y. Lin, S. Monti, M. G. M. Roemer, J. Qi, P. B. Rahl, H. H. Sun, K. T. Yeda, J. G. Doench, E. Reichert, A. L. Kung, S. J. Rodig, R. A. Young, M. A. Shipp and J. E. Bradner, Cancer Cell, 2014, 25, 545-546.

209 J. Loven, H. A. Hoke, C. Y. Lin, A. Lau, D. A. Orlando, C. R. Vakoc, J. E. Bradner, T. I. Lee and R. A. Young, Cell, 2013, 153, 320-334.
210 J. E. Delmore, G. C. Issa, M. E. Lemieux, P. B. Rahl, J. W. Shi, H. M. Jacobs, E. Kastritis, T. Gilpatrick, R. M. Paranal, J. Qi, M. Chesi, A. C. Schinzel, M. R. McKeown, T. P. Heffernan, C. R. Vakoc, P. L. Bergsagel, I. M. Ghobrial, P. G. Richardson, R. A. Young, W. C. Hahn, K. C. Anderson, A. L. Kung, J. E. Bradner and C. S. Mitsiades, Cell, 2011, 146, 903-916.

211 J. A. Mertz, A. R. Conery, B. M. Bryant, P. Sandy, S. Balasubramanian, D. A. Mele, L. Bergeron and R. J. Sims, Proc. Natl. Acad. Sci. U. S. A., 2011, 108, 16669-16674.

212 A. Chaidos, V. Caputo, K. Gouvedenou, B. B. Liu, I. Marigo, M. S. Chaudhry, A. Rotolo, D. F. Tough, N. N. Smithers, A. K. Bassil, T. D. Chapman, N. R. Harker, O. Barbash, P. Tummino, N. Al-Mahdi, A. C. Haynes, L. Cutler, B. C. Le, A. Rahemtulla, I. Roberts, M. Kleijnen, J. J. Witherington, N. J. Parr, R. K. Prinjha and A. Karadimitris, Blood, 2014, 123, 697-705.

213 J. Zuber, J. W. Shi, E. Wang, A. R. Rappaport, H. Herrmann, E. A. Sison, D. Magoon, J. Qi, K. Blatt, M. Wunderlich, M. J. Taylor, C. Johns, A. Chicas, J. C. Mulloy, S. C. Kogan, P. Brown, P. Valent, J. E. Bradner, S. W. Lowe and C. R. Vakoc, Nature, 2011, 478, 524-528.

214 A. Puissant, S. M. Frumm, G. Alexe, C. F. Bassii, J. Qi, Y. H. Chanthery, E. A. Nekritz, R. Zeid, W. C. Gustafson, P. Greninger, M. J. Garnett, U. McDermott, C. H. Benes, A. L. Kung, W. A. Weiss, J. E. Bradner and K. Stegmaier, Cancer Res., 2013, 73, 308-323.

215 P. Filippakopoulos, J. Qi, S. Picaud, Y. Shen, W. B. Smith, O. Fedorov, E. M. Morse, T. Keates, T. T. Hickman, I. Felletar, M. Philpott, S. Munro, M. R. McKeown, Y. Wang, A. L. Christie, N. West, M. J. Cameron, B. Schwartz, T. D. Heightman, N. La Thangue, C. A. French, O. Wiest, A. L. Kung, S. Knapp and J. E. Bradner, Nature, 2010, 468, 1067-1073.

216 P. P. G. Sharp, J.-M. Garnier, T. Hatfaludi, Z. Xu, D. Segal, K. E. Jarman, H. Jousset, A. Garnham, J. T. Feutrill, A. Cuzzupe, P. Hall, S. Taylor, C. R. Walkley, D. Tyler, M. A. Dawson, P. Czabotar, A. F. Wilks, S. Glaser, D. C. S. Huang and C. J. Burns, ACS Med. Chem. Lett., 2017, 8(12), 1298-1303.

217 T. D. Crawford, F. A. Romero, K. W. Lai, V. Tsui, A. M. Taylor, G. de Leon Boenig, C. L. Noland, J. Murray, J. Ly, E. F. Choo, T. L. Hunsaker, E. W. Chan, M. Merchant, S. Kharbanda, K. E. Gascoigne, S. Kaufman, M. H. Beresini, J. Liao, W. Liu, K. X. Chen, Z. Chen, A. R. Conery, A. Cote, H. Jayaram, Y. Jiang, J. R. Kiefer, T. Kleinheinz, Y. Li, J. Maher, E. Pardo, F. Poy, K. L. Spillane, F. Wang, J. Wang, X. Wei, Z. $\mathrm{Xu}$, Z. Xu, I. Yen, L. Zawadzke, X. Zhu, S. Bellon, R. Cummings, A. G. Cochran, B. K. Albrecht and S. Magnuson, J. Med. Chem., 2016, 59, 10549-10563.

218 T. A. Popp, C. Tallant, C. Rogers, O. Fedorov, P. E. Brennan, S. Muller, S. Knapp and F. Bracher, J. Med. Chem., 2016, 59, 8889-8912.

219 I. Navratilova, T. Aristotelous, S. Picaud, A. Chaikuad, S. Knapp, P. Filappakopoulos and A. L. Hopkins, ACS Med. Chem. Lett., 2016, 7, 1213-1218. 